\title{
Movement is Improvement: The Therapeutic Effects of Exercise and General Physical Activity on Glycemic Control in Patients with Type 2 Diabetes Mellitus: A Systematic Review and Meta-Analysis of Randomized Controlled Trials
}

\author{
Sayed Z. A. Shah · Jawad A. Karam • Alam Zeb · Rafi Ullah • \\ Arif Shah · Ijaz Ul Haq · Iftikhar Ali · Haider Darain · Hong Chen
}

Received: November 10, 2020 / Accepted: January 15, 2021 / Published online: February 5, 2021

(C) The Author(s) 2021

\section{ABSTRACT}

Introduction: Exercise is considered a cornerstone in achieving an optimized blood glucose level and reducing body weight, body mass index (BMI), and waist circumference. This study aimed to investigate and quantitatively

S. Z. A. Shah · H. Chen $(\bowtie)$

Department of Rehabilitation Medicine, Tongji

Hospital, Tongji Medical College, Huazhong

University of Science and Technology, Wuhan,

People's Republic of China

e-mail: chenhong1129@hotmail.com;

chenhong1129@hust.edu.cn

\section{J. A. Karam}

Department of applied exercise science, Concordia University Chicago, 7400 Augusta St., River Forest, IL 60305, United States

\section{A. Zeb}

School of Health Sciences, Peshawar, Pakistan

R. Ullah · A. Shah · I. U. Haq · I. Ali

Paraplegic Centre, Phase\#4, Hayatabad, Peshawar, Pakistan

\section{H. Darain}

Institute of Physical Medicine and Rehabilitation Sciences, Khyber Medical University, Hayatabad, Peshawar, Pakistan

\section{H. Chen}

WHO Collaborating Center for Training and Research in Rehabilitation, Tongji Hospital, Tongji Medical College, Huazhong University of Science and Technology, Wuhan, People's Republic of China summarize the literature regarding the therapeutic effects of exercise and general physical activity on glycemic control.

Methods: A systematic review and meta-analysis of the literature on the therapeutic effects of exercise on glycemic control in patients with type 2 diabetes mellitus (type $2 \mathrm{DM}$ ) were conducted using electronic databases. Studies with an exercise intervention lasting more than 8 weeks were included. Both qualitative and quantitative analyses were performed. Qualitative data were presented narratively in table form. Quantitative analysis was performed using a random-effects model with a $95 \%$ confidence interval and a significance level of 0.05 . The Physiotherapy Evidence Database (PEDro) scale and the Cochrane Risk of Bias 2 (RoB2) tool were used to assess the quality of evidence and the risk of bias.

Results: A total of 21,559 articles were identified through different databases. Out of 21559 studies, only 32 randomized controlled trials were deemed eligible for inclusion in this study. The average exercise session was $45.15 \mathrm{~min}$, while the average follow-up duration was 21.94 weeks. The mean exercise frequency according to our findings was 3.25 days/week. Almost all the studies reported decreases in glycated hemoglobin (HbA1c; $P<0.0001$ ), fasting blood glucose $(P=0.03)$, BMI $(P=0.04)$, and waist circumference $(P=0.007)$ after the exercise intervention. 
Conclusion: Exercise plays an important role in optimizing glycemic control and improving quality of life (QoL), BMI, and waist circumference in type $2 \mathrm{DM}$ patients. Exercise could be a safe adjunct therapy to medical treatments in these patients.

Registration: PROSPERO: CRD42020210816

Keywords: Diabetes mellitus, type 2; Exercise; Fasting blood glucose; Glycated hemoglobin; Meta-analysis; Physical activity; Systematic review

\section{Key Summary Points}

Why carry out this study?

Exercise is considered a cornerstone in type 2 DM management, but diabetes patients are increasingly likely to lead a sedentary lifestyle.

This study investigated the effects of different exercise regimens on glycemic control, anthropometric parameters, and quality of life for type $2 \mathrm{DM}$ patients.

\section{What was learned from the study?}

Exercise significantly affects glycemic control, induces beneficial anthropometric changes, and enhances quality of life.

General physical activity and walking are considered low-impact activities, but they can still benefit type 2 DM patients.

\section{DIGITAL FEATURES}

This article is published with digital features, including a summary slide, to facilitate understanding of the article. To view digital features for this article go to https://doi.org/10.6084/ m9.figshare.13574684.

\section{INTRODUCTION}

Diabetes mellitus (DM), a very common medical condition, is associated with decreased production of insulin or an inability of the body to utilize it properly (types 1 and $2 \mathrm{DM}$, respectively) [1]. Type $2 \mathrm{DM}$ is the most prevalent form of diabetes, accounting for nearly $90 \%$ of all cases of diabetes [2, 3]. According to statistics from the International Diabetes Federation (IDF), the estimated combined global prevalence of type 1 and type $2 \mathrm{DM}$, both diagnosed and undiagnosed, was 463.0 million adults aged 20-79 years in 2019. Based on this 2019 estimation, a prevalence of 578.4 million is projected by the year 2030, and if the present trend continues, 700.2 million adults aged 20-79 years will be diabetic by 2045 [4]. The reason behind this escalation of the prevalence of diabetes could be sedentary lifestyles, increasing levels of obesity, aging populations, and diets that are high in calories and fat [5].

Body mass index (BMI) and waist hip ratio (WHR) are independent risk factors for type 2 DM [6]. In developed countries, diabetes mostly occurs in the elderly, while in developing countries, diabetes mostly affects people aged 34-65 years [7]. It is often reported that a high proportion of patients with diabetes perform only a small amount of physical activity, including structured exercises [3]. Type $2 \mathrm{DM}$ is a major cause of premature morbidity and mortality associated with cardiovascular disorders, kidney diseases, neuropathies, retinopathy, and amputation [5]. Along with other complications, diabetic patients may also suffer from depression, anxiety, denial, worries, and frustration [1]. Poor health management services and a lack of awareness of diabetes can increase diabetes-related mortality [8]. Diabetes mellitus has increased the socioeconomic burden on developing countries [9], and is considered to be a prime reason for increasing healthcare costs worldwide [10]. Diabetes drugs are expensive, and most patients fail to get high-quality treatment due to the expensive nature of the treatment, the poor allocation of funds for healthcare, and the lack of medical reimbursement in developing countries [11].

Studies have shown that regular exercise can delay diabetes and associated complications, but it has been observed that most diabetic patients are inactive. Generally speaking, diabetic patients can attain a controlled level of 
blood sugar by adopting a healthy nutritional plan, exercising regularly, and reducing body weight, although some may need to use exogenous insulin [12].

According to Gabriel and Zierath [13], the acute effects of exercise include enhanced glucose metabolism and improved insulin sensitivity. Blood glucose was found to be an important substrate in the skeletal muscle oxidation process during strenuous exercise, and exercising increases glucose utilization without affecting blood insulin levels. Exercise also increases certain protein levels that are important for glucose homeostasis. The increase in the level of glucose transporter type 4 protein (GLUT4) induced by exercise training enhances skeletal muscle glucose uptake. This strategy could regulate blood glucose levels in the case of insulin resistance. Gabriel and Zierath also noted that performing exercise training for longer increases the aerobic threshold and the concentration of mitochondria in skeletal muscles [13]. Exercise has long been considered the cornerstone of diabetes mellitus management, along with diet adjustment and drug treatment. Aerobic exercise, which consists of exercising large groups of muscles in a rhythmic, repeated, and continuous manner for at least $10 \mathrm{~min}$, is used in diabetes management. In strenuous short-duration exercise, muscles mainly use energy from the glycogen stores, but the muscle glycogen stores are gradually depleted during long-duration exercise, so energy is mainly provided by glucose and free fatty acids from adipose tissues [13, 14]. High-intensity exercise consumes glucose at a higher rate than it is produced by the liver, so the blood sugar level drops [14]. It has been proven that exercise increases the sensitivity of muscle cells to insulin and increases the activity of oxidative enzymes [5]. Moreover, the overall effects of exercise on carbohydrate metabolism are associated with improved insulin sensitivity [15].

The results of a randomized controlled trial of adults with type 2 diabetes that explored the benefits of aerobic or resistance training alone or combined indicated that both types of exercise training alone improved glycemic control, but the improvement was greatest with combined resistance and aerobic training [16].
The increase in glucose uptake by skeletal muscles, enhanced insulin sensitivity, and improved oxidative enzyme activity during exercise are the rationale for incorporating exercise as a therapeutic adjunct into the management of type $2 \mathrm{DM}$. The purpose of this systematic review and meta-analysis was to investigate and quantitatively summarize the literature regarding the therapeutic effects of exercise and general physical activity on glycemic control, exercise-associated anthropometric changes, and the quality of life of type $2 \mathrm{DM}$ patients.

\section{METHODS}

A systematic review and meta-analysis of randomized controlled trials was conducted according to the Preferred Reporting Items for Systematic Reviews and Meta-Analyses (PRISMA) 2009 guidelines [17]. This study was registered with PROSPERO (registration ID: CRD42020210816).

\section{Study Objective}

To explore and quantitatively summarize the literature regarding the therapeutic effects of exercise and general physical activity on glycemic control, exercise-associated anthropometric changes, and quality of life of type $2 \mathrm{DM}$ patients.

\section{Study Question}

Do exercise and general physical activity have beneficial therapeutic effects on the glycemic control, anthropometric parameters, and quality of life of type $2 \mathrm{DM}$ patients?

\section{PICO}

P (Population): Type 2 DM patients

I (Intervention): Exercise and general physical activity or combinations of exercise with other therapies

C (Comparison): Nonexercise/standard treatment/placebo, or different exercise regimen groups of type $2 \mathrm{DM}$ patients 
O (Outcomes): HbA1c, fasting blood glucose (FBG), quality of life (QOL), BMI, weight, waist circumference.

\section{Search Strategy}

The electronic databases AMED, Embase, HMIC, BNI, MEDLINE, PsycInfo, CINAHL, HEALTH BUSINESS, PubMed, Web of Science (WoS), and EBSCO were used to conduct a systematic literature search. The limits applied were publication year (2011-2020), English language studies, and human studies. Another method of identifying relevant studies was to screen the reference lists of studies retrieved from the databases. We included studies up to the year 2000 identified through screening the reference lists of the studies retrieved from the databases. A search alert was created for Web of Science and EBSCO to retrieve recently published studies. The following keywords and MeSH terms were identified for every database individually and used during the searches: "physical activity," "exercise," "diabetes mellitus," "type 2." Another method of identifying relevant studies was to screen the reference lists of the studies retrieved from the databases.

\section{Study Selection}

\section{Inclusion and Exclusion Criteria}

The study inclusion criteria were as follows: (1) randomized controlled trials (RCTs) that studied the effects of exercise on glycemic control in patients with type $2 \mathrm{DM}$ and had a follow-up period of $\geq 8$ weeks; (2) participants of any age and gender; and (3) quantitative measurement of glycemic control or anthropometric changes. The following studies were excluded: studies with a diabetes mellitus type 1 population, single-arm studies, animal studies, ex vivo/ in vitro studies, review studies, retrospective studies, and case studies.

\section{Types of Intervention}

Exercise, walking, or general physical activity compared with the nonexercise control group or the use of other treatments or exercise interventions. Studies combining other therapies with exercise, walking, or physical activity were also included.

\section{Types of Participants}

Studies with type 2 DM patients were included; studies where all subjects were only at risk of diabetes were excluded.

\section{Types of Outcome Measures}

The primary study variable was $\mathrm{HbA} 1 \mathrm{c}$, and secondary outcomes were FBG, QOL, BMI, bodyweight, and waist circumference.

\section{Study Selection Process}

The study selection process comprised three screening phases: study title screening, abstract screening, and, finally, full-text screening. There were two independent reviewers at each screening phase. The corresponding author resolved any conflicts or disagreements between the two reviewers. The search results were uploaded to Rayyan QCRI (https://www.rayyan. qcri.org: Data Analytics, Qatar Computing Research Institute) for citation screening by two independent reviewers [18]. After screening the titles, the abstracts of the selected titles were screened. Finally, the full texts of the selected studies were screened in detail for relevancy.

\section{Study Quality and Risk of Bias Assessment}

Data extracted for external validity and reporting quality assessment included study ID (first author's name along with the year and reference), study design characteristics (data regarding experimental design and study groups, number of participants per group), participant details, intervention (types of exercise, intensity, frequency, and follow-up), control (control type and control intervention details), primary and secondary outcome measures, and information regarding adverse events.

The Physiotherapy Evidence Database (PEDro) scale was used for study quality assessment [19]. Two independent reviewers performed the study quality evaluation; any conflicts/disagreements were resolved by comparing the recorded data and through 
discussion with the corresponding author. The PEDro scale has 11 quality assessment items (yes or no), of which 10 are used to calculate the final PEDro score (0-10). Sackett's levels of evidence were used to simplify the study quality levels, and a study was considered to be level 1 (higher quality) if it scored $\geq 6$ on the PEDro scale and level 2 if it scored $<6$ [20].

The risk of study bias was assessed by two independent reviewers using the Cochrane risk of bias (RoB 2) tool [21]. Every study was rated with the RoB 2 tool for selection bias, detection bias, performance bias, outcome assessment, incomplete data, outcome reporting, and other threats to study validity identified by two reviewers. The risk of bias was categorized as either a low risk of bias (the domain was considered adequate), a high risk of bias (the domain was considered inadequate), or an unclear risk of bias (not enough information to make a judgment about the bias). The RoB 2 Excel tool was filled for individual studies, and the results were entered into Cochrane Review Manager 5.3 [22].

\section{Data Extraction}

For the study of primary and secondary variables, postintervention means and standard deviations (SD) as well as sample size details were retrieved by two independent reviewers. Any conflicts/disagreements were resolved through discussion with the corresponding author and by comparing the recorded data. The Microsoft data extraction form included the following details of the included studies: study design, population details, target variables, interventional procedures (study groups, exercise type, volume, and intensities), and study findings. The authors prepiloted the data extraction form in some studies. Data were extracted from the texts, tables, and figures of the included studies.

\section{Data Synthesis}

We performed both qualitative and quantitative analyses. The data extracted were summarized in table form to effectively present the characteristics and results of the included studies. To study the primary and secondary variables, a meta-analysis was performed using a random-effects model.

\section{Meta-Analysis}

Quantitative analysis was performed for the study's primary outcome measure (HbA1c) and the secondary outcome measures (FBGs, BMI, weight, and waist circumference). The means and standard deviations of outcomes from the exercise and control groups were compared using mean differences and a random-effects model with a $95 \%$ confidence interval. The time points for data extraction regarding the primary and secondary variables were not specified, but we preferred time points of 8 weeks and above. For some studies where the standard deviations (SD) were not provided, we calculated SDs with an online calculator using the formula provided by Hozo et al. [23].

Effect sizes of $0.2,0.5$, and 0.8 were considered small, moderate, and large, respectively [24]. $I^{2}$ and the chi-square test were used to evaluate heterogeneity among the studies. We considered an $I^{2}$ value of $25 \%$ to indicate low heterogeneity, $50 \%$ to represent moderate heterogeneity, and $75 \%$ to indicate high heterogeneity [25]. All the analyses were performed in Cochrane Review Manager 5.3 [22], and $p<0.05$ was taken to indicate statistical significance.

\section{Compliance with Ethics Guidelines}

This study is based on previous studies; the authors did not perform any clinical or preclinical experiment involving humans or animals.

\section{RESULTS}

\section{Study Selection}

The research databases AMED, Embase, HMIC, BNI, MEDLINE, PsycInfo, CINAHL, HEALTH BUSINESS, PubMed, Web of Science (WoS), and 
EBSCO were used to conduct a systematic literature search. The search retrieved 21,559 articles. A total of 32 articles were also identified from the reference lists of other studies. 1448 duplicates were identified using Rayyan QCRI and EndNote. Title and abstract screening by two independent reviewers resulted in the exclusion of a further 20,063 studies. Eighty articles were deemed eligible for full-text screening, while 48 were excluded for particular reasons. Finally, 32 articles were eligible for inclusion in the systematic review, and 26 in the meta-analysis (see the PRISMA flow diagram in Fig. 1).
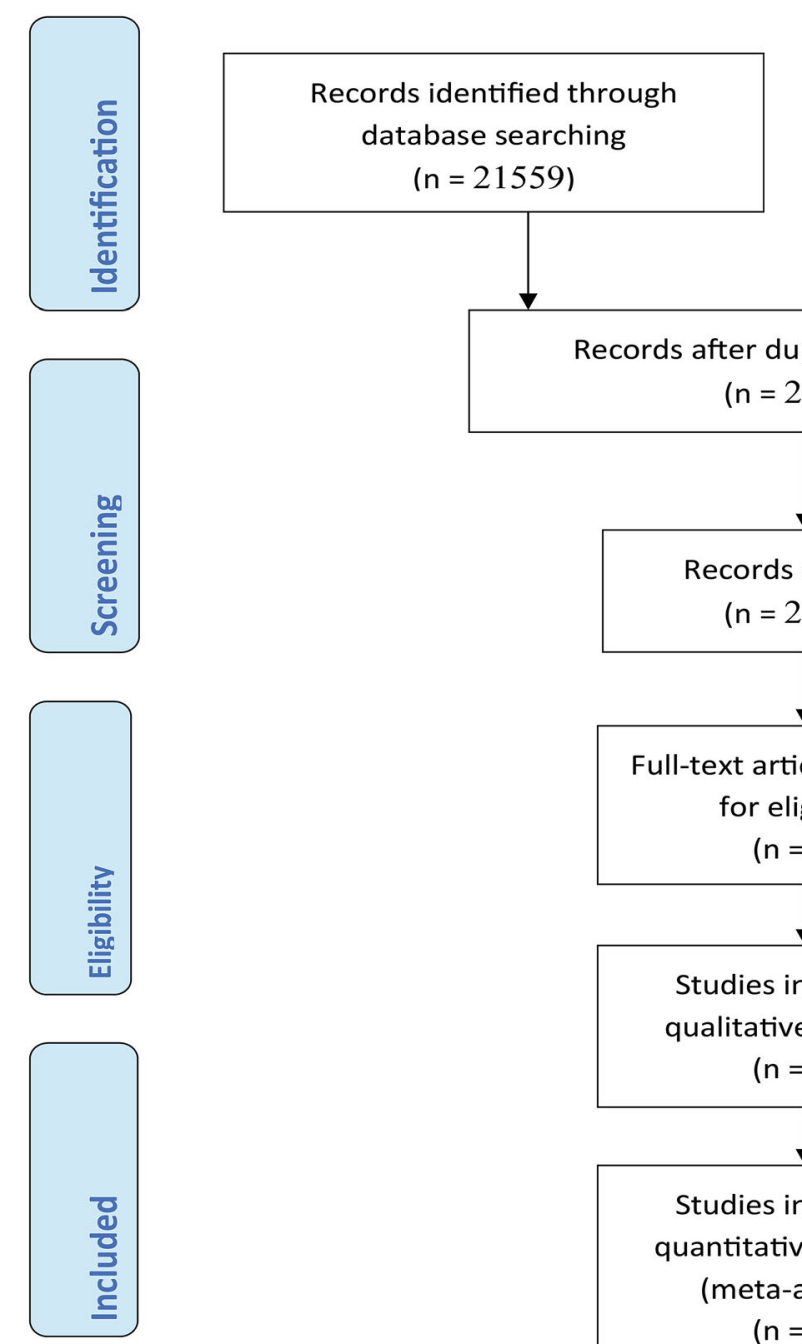

\section{Study Characteristics}

The average age calculated from 26 studies was 57.36 years. Two studies recruited participants in the age ranges 30-80 years [26] and 40-65 years [27], respectively; another recruited elderly patients above 50 years [28]. The average exercise session was $45.15 \mathrm{~min}$, while the average follow-up duration was 21.94 weeks. The mean exercise frequency according to our findings was 3.25 days/week.

For all studies, the study population comprised type $2 \mathrm{DM}$ patients. Depending on the study, the participants were also obese [29], hypertensive [30], adults with coronary artery

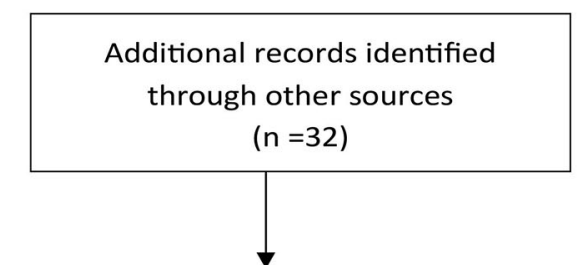

Records after duplicates removed

$(n=20143)$

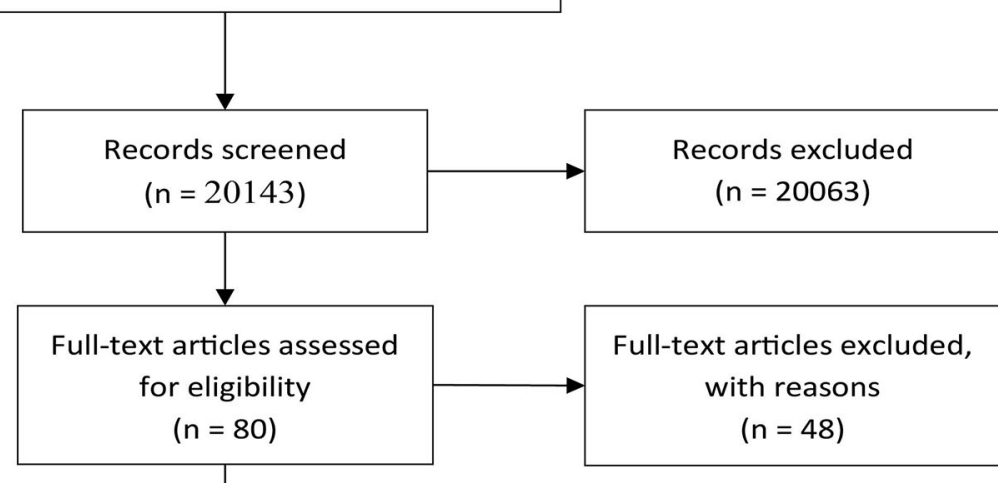

Studies included in

qualitative synthesis

$(n=32)$

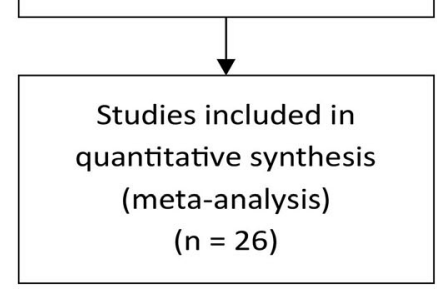

Fig. 1 PRISMA flow diagram depicting the study selection process 
disease (CAD) [31], or newly diagnosed type 2 DM patients [32], had received their diagnosis 5-8 months earlier [26] or $<5$ years earlier [33], or were female participants only [34], sedentary patients with 5 years of diagnosis [35], elderly patients with peripheral neuropathy [28], or overweight, dysregulated, and sedentary patients [36]. Most of the studies recruited participants with HbA1c levels of 6.4-7.0 $[26,30,32,37-44]$, followed by levels of $\geq 6.5$ $[27,45,46], 7.0-10.0$ [34], 7.2-9.0 [28, 31, $33,47], 10.0-11.0[48,49]$, or 7.0-11.0 [36].

A variety of exercise interventions were utilized in the studies, but aerobic training (12 studies) $[27,28,30,32,39,41,44,45,49-52]$ and resistance training (RT) (14 studies) [27, 31, 36, 39-41, 44, 45, 47, 48, 52-55] were the most common. More specifically, the exercises used in the studies were as follows: aerobic exercises: moderate-intensity continuous (MIC) training [30, 32], supervised structured aerobic exercise training (SSAET) [51]; anaerobic training: 5 studies [32, 37, 55-57], high-intensity interval training (HIIT) [30, 32, 37, 56], sprint interval training (SIT) [32]; resistance training (RT): biodensity resistance exercise [40], progressive resistance training (PRT) [53, 54]; endurance training: 1 study [37]; combined exercise training: combined exercise regimen [38, 44, 45, 47]; walking: [29, 31, 39, 43, 45, 46]; general physical activity: [26, 31, 33, 42, 44]; nonlocomotive physical activity [42]; yoga: [34, 43]; and nonspecific exercises [35].

The common outcome measures used by most of the studies were as follows: HbA1c (all studies), FBG (20 studies) [26-29, 32, 35-37, $40,42-44,47,48,50-52,56-58]$, BMI (17 studies) $[27,29,30,34-38,44,45,48,50$, 51, 54-57], bodyweight (13 studies) $[26,27,31,33,35,36,42,44,45,48,54,56,57]$, waist circumference (11 studies) [26, 29, 33, 35, 41, 44, 45, 47, 48, 53, 54, 56], and QoL (5 studies) [33, 36, 43, 48, 54].

The durations of interventions reported by the included studies were as follows: $8-12$ weeks $[27,28,30,35,37,38,42,43,48,55-57], 16-$ 25 weeks $[36,37,44,50,51,53]$, and 6 months to 1 year [26, 29, 31, 39-41, 46, 52]. Three days per week $(3 \mathrm{~d} / \mathrm{wk})[30,32,35-38,41,45-48$, $51,53-55,57]$ was the most common exercise frequency, followed by $5 \mathrm{~d} / \mathrm{wk},[39,50,56], 1 \mathrm{~d} /$ wk [59], and 2d/wk [31, 34, 43], daily [29], 7 visits/3 month [44], and $1 \mathrm{~d} / 5$ weeks [44]. Most of the studies were consistent in the duration of an exercise session: 5-10 $\mathrm{min}$ [40], 20-45 $\mathrm{min}$ $[30,32,35,37,38,44,47,49,50], 45-60 \mathrm{~min}$ $[27,31,34,36,39,43,51,55,56], 270 \mathrm{~min} / \mathrm{wk}$ [41], or $150 \mathrm{~min} / \mathrm{wk}[33,45,52]$.

Progression and increasing intensity of exercise were reported by 12 studies as follows: based on an increasing number of steps at each visit [29]; based on monitoring body weight and maximum oxygen uptake $\left(\mathrm{VO}_{2}\right.$ max) every three months, progression from $70 \%$ to $80 \%$ HRR was observed [47]; based on increased exercise intensity with every session [32]; based on increasing the mean treadmill grade and METs progressively [41]; based on a progressive increase in resistance [53, 56]; based on an individualized elevation of exercise intensity (14-16 on the Borg scale) at week 12 [48]; based on a 30-min increase in each phase of a fivephase program [51]; based on increasing nonlocomotive physical activity [42]; based on progression in the completion of 12 repetitions during the final set of exercises in two consecutive sessions [45]; and based on the progression of low-volume HIIT to high-volume HIIT over 6-12 weeks [55]. A detailed description of the study characteristics is available in Table 1.

\section{Study Quality and Risk of Bias}

The selection, performance, and detection biases were similar for most of the studies (Fig. 2, $3)$. The quality and level of evidence of each study are summarized in Table 2 . The majority (26) of the studies were of high quality (level 1), but 6 studies were of lower quality (level 2) $[33,39,42,44,45,57]$. 


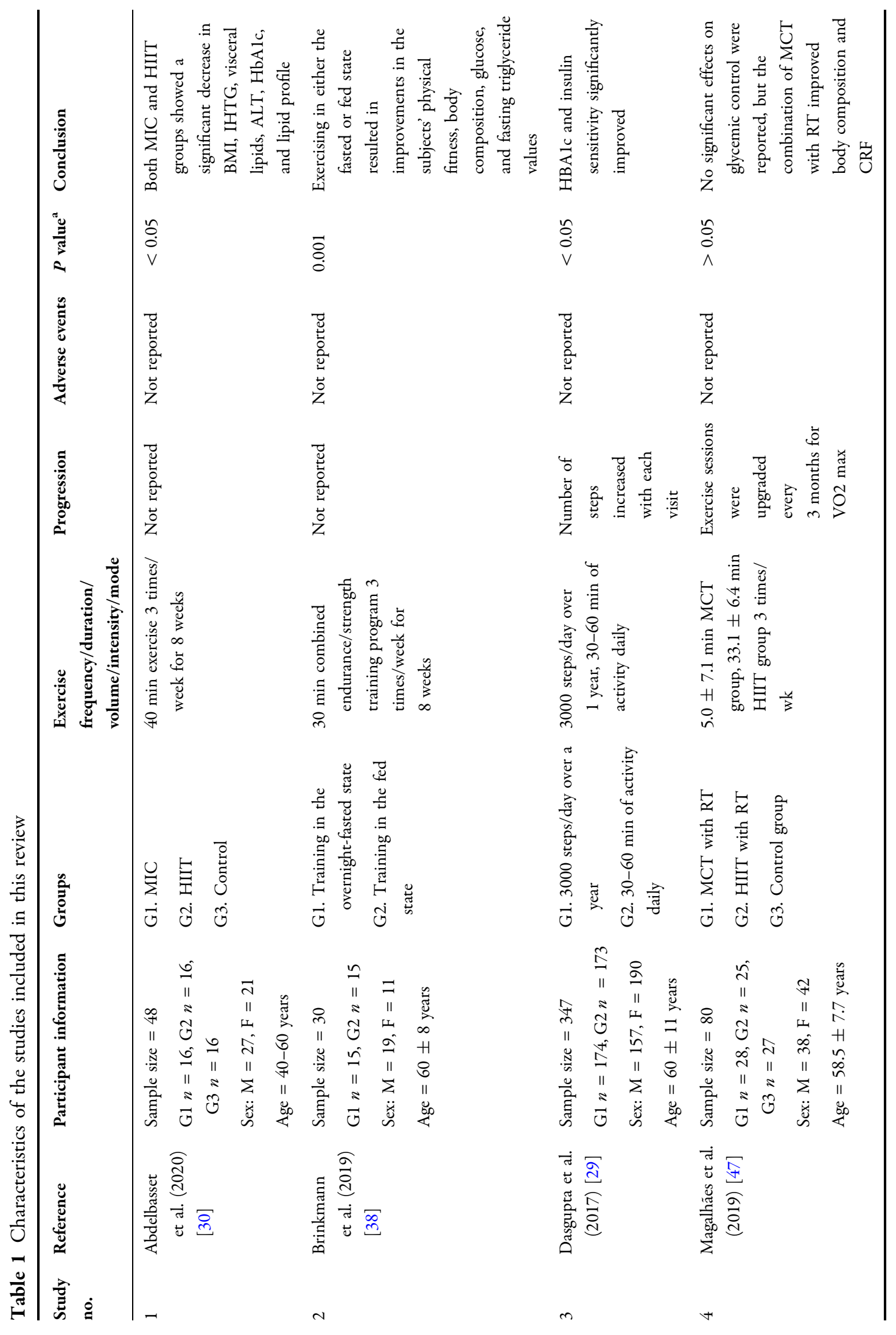




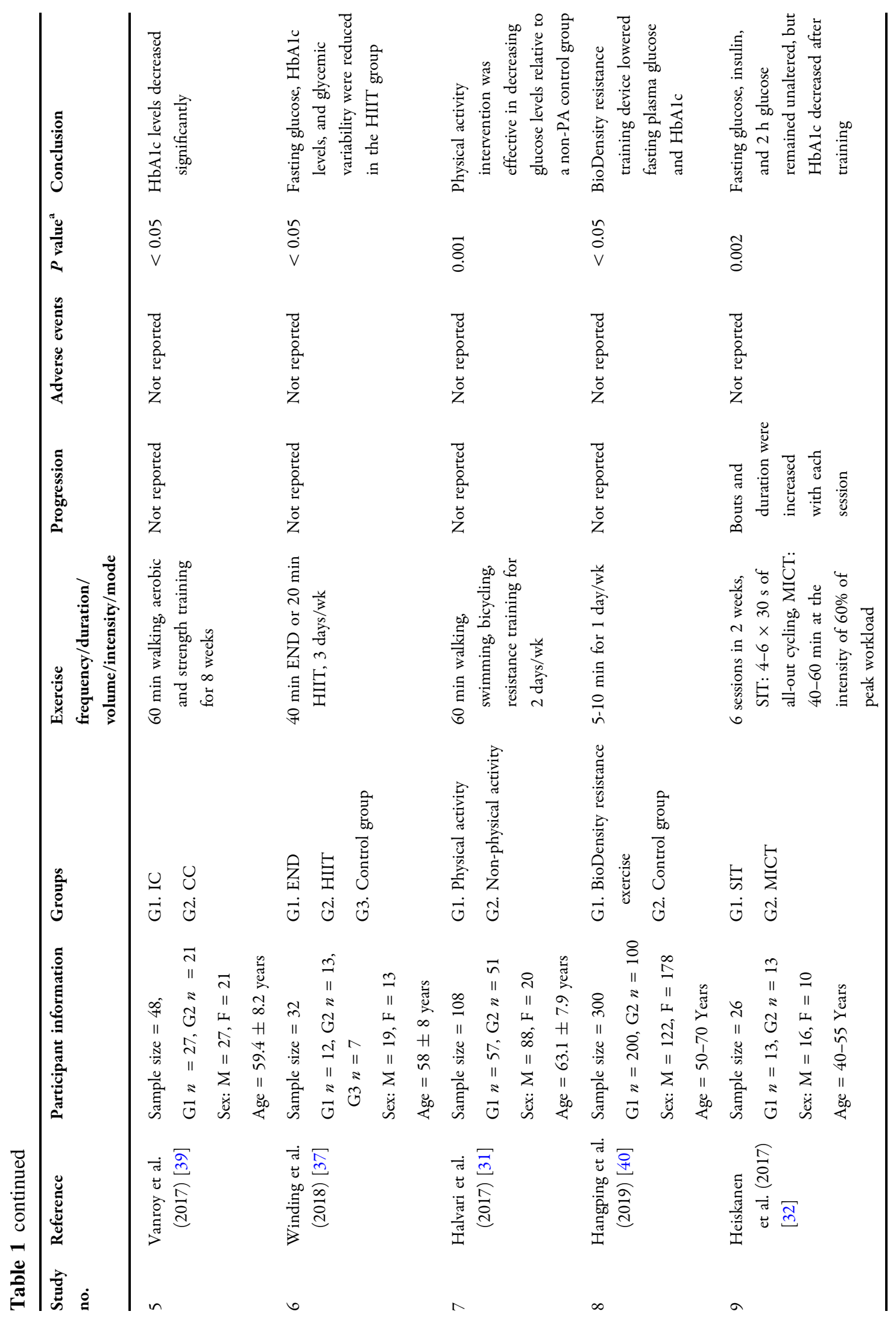




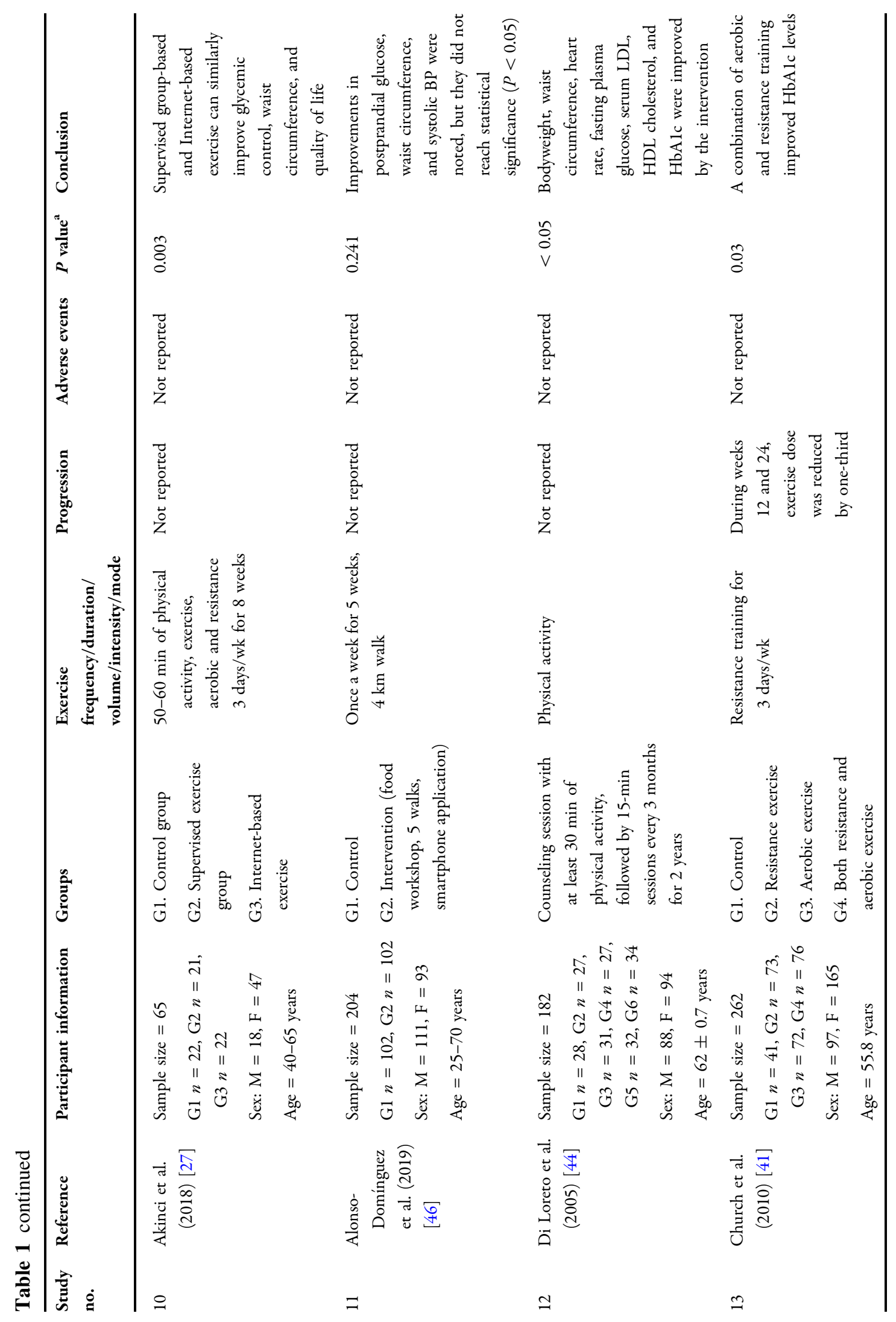




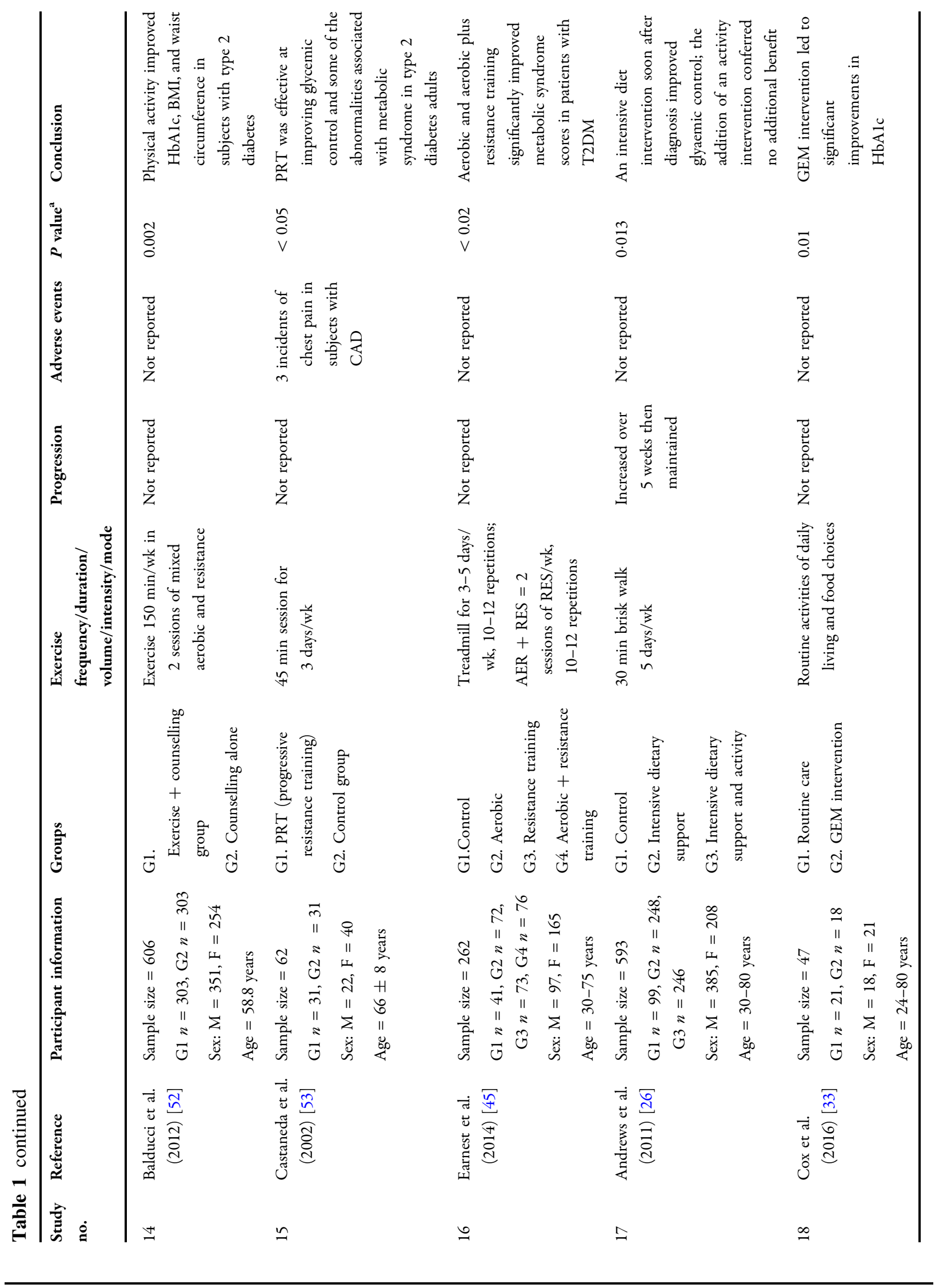




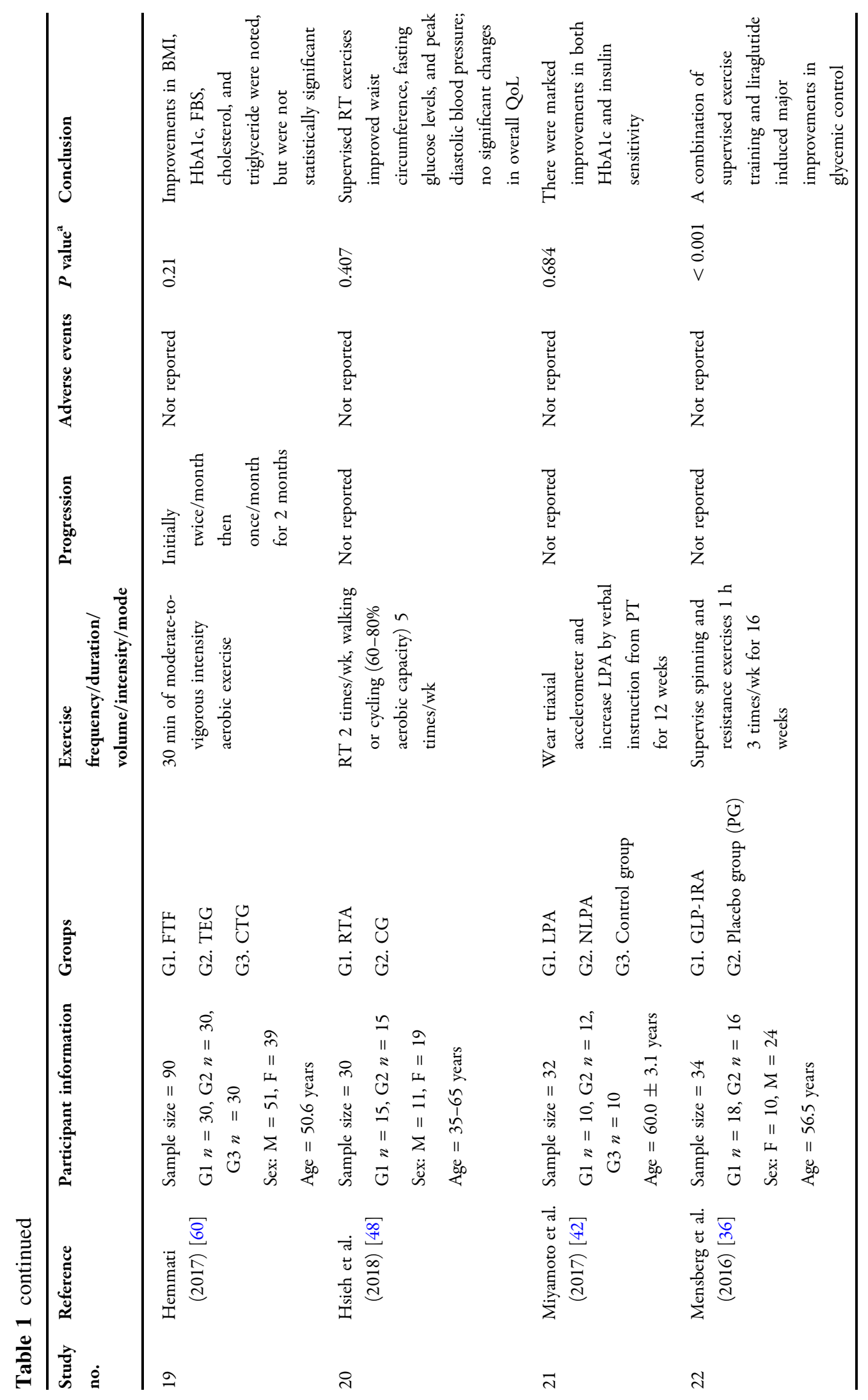




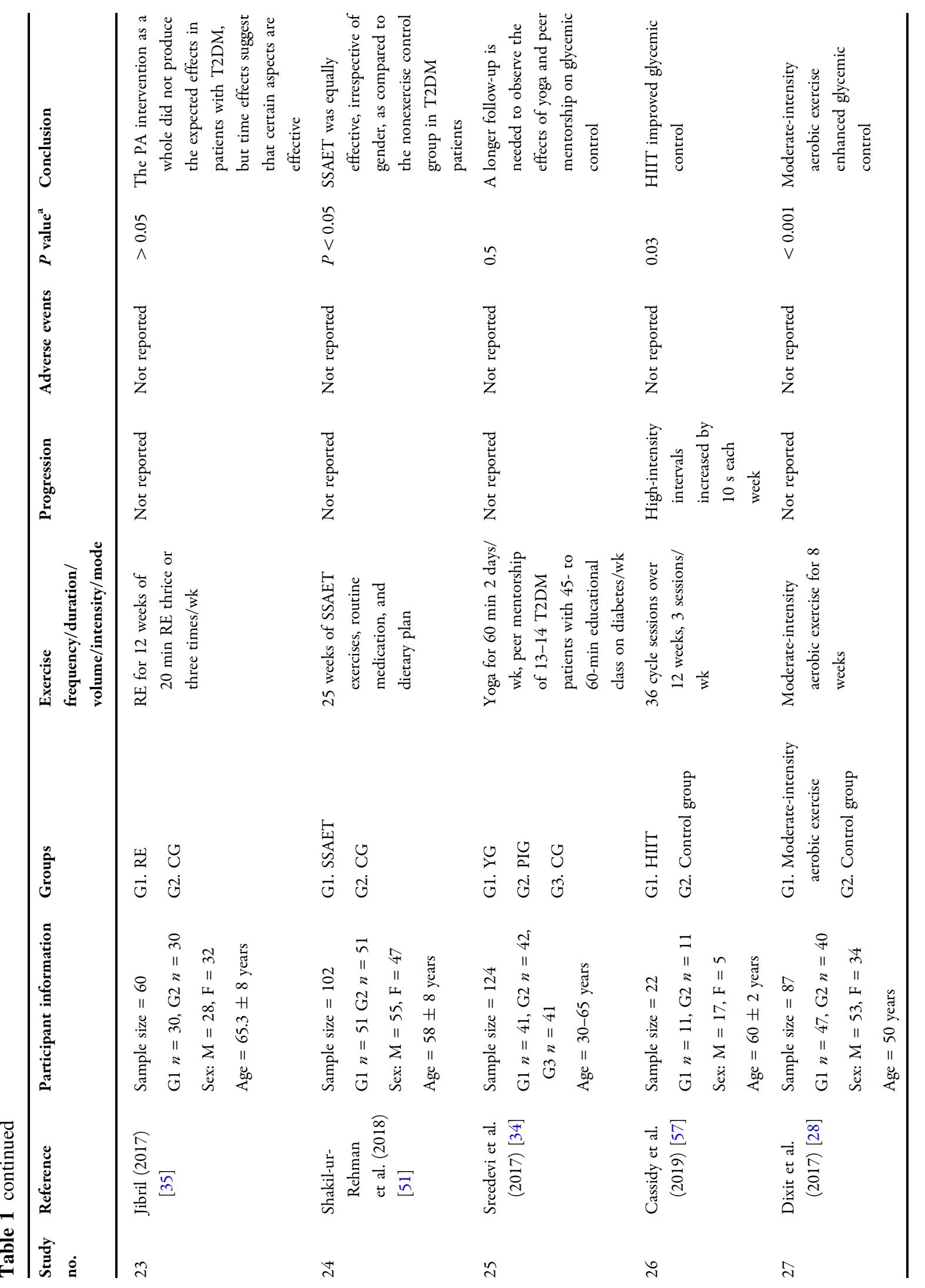




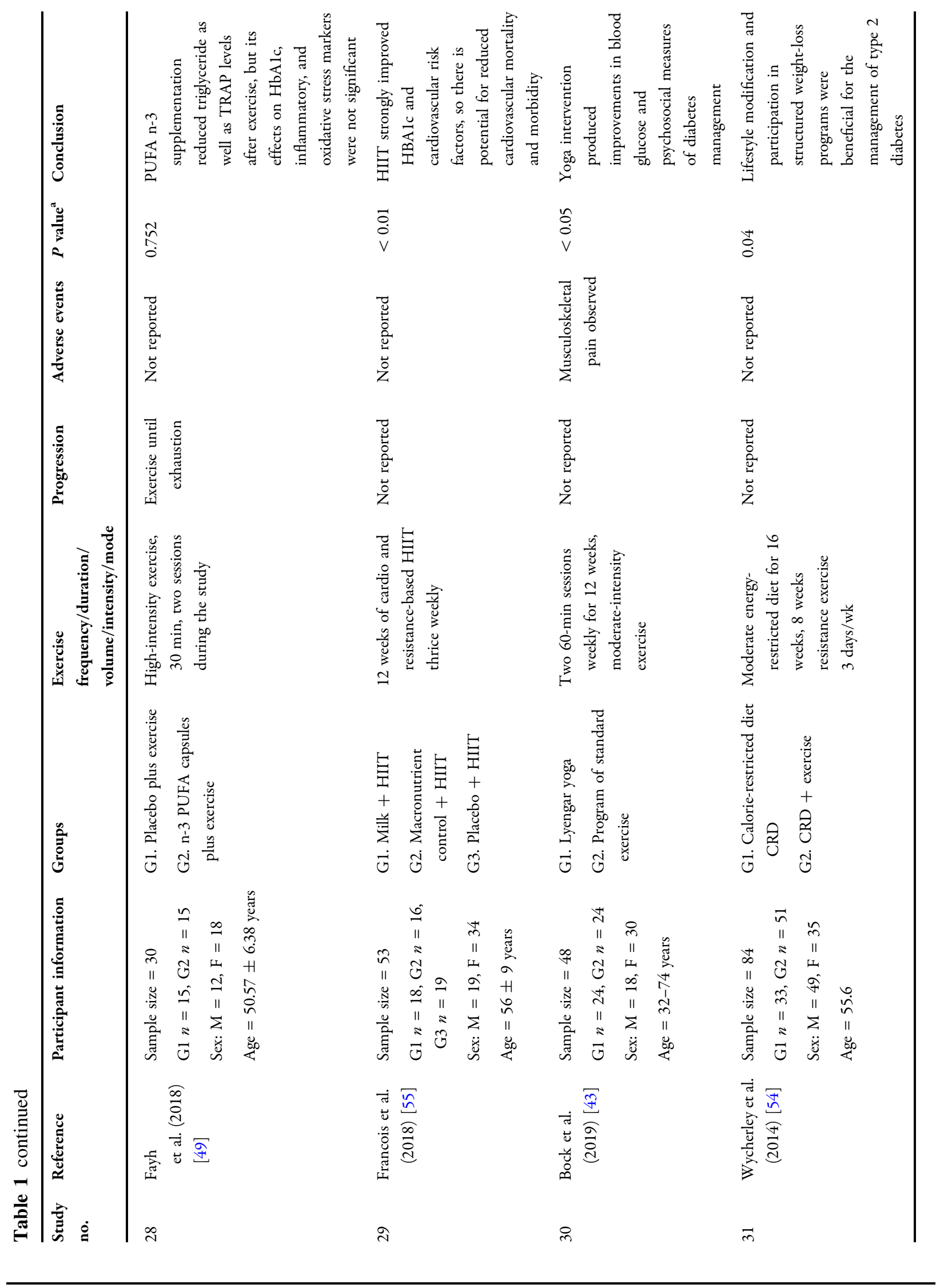




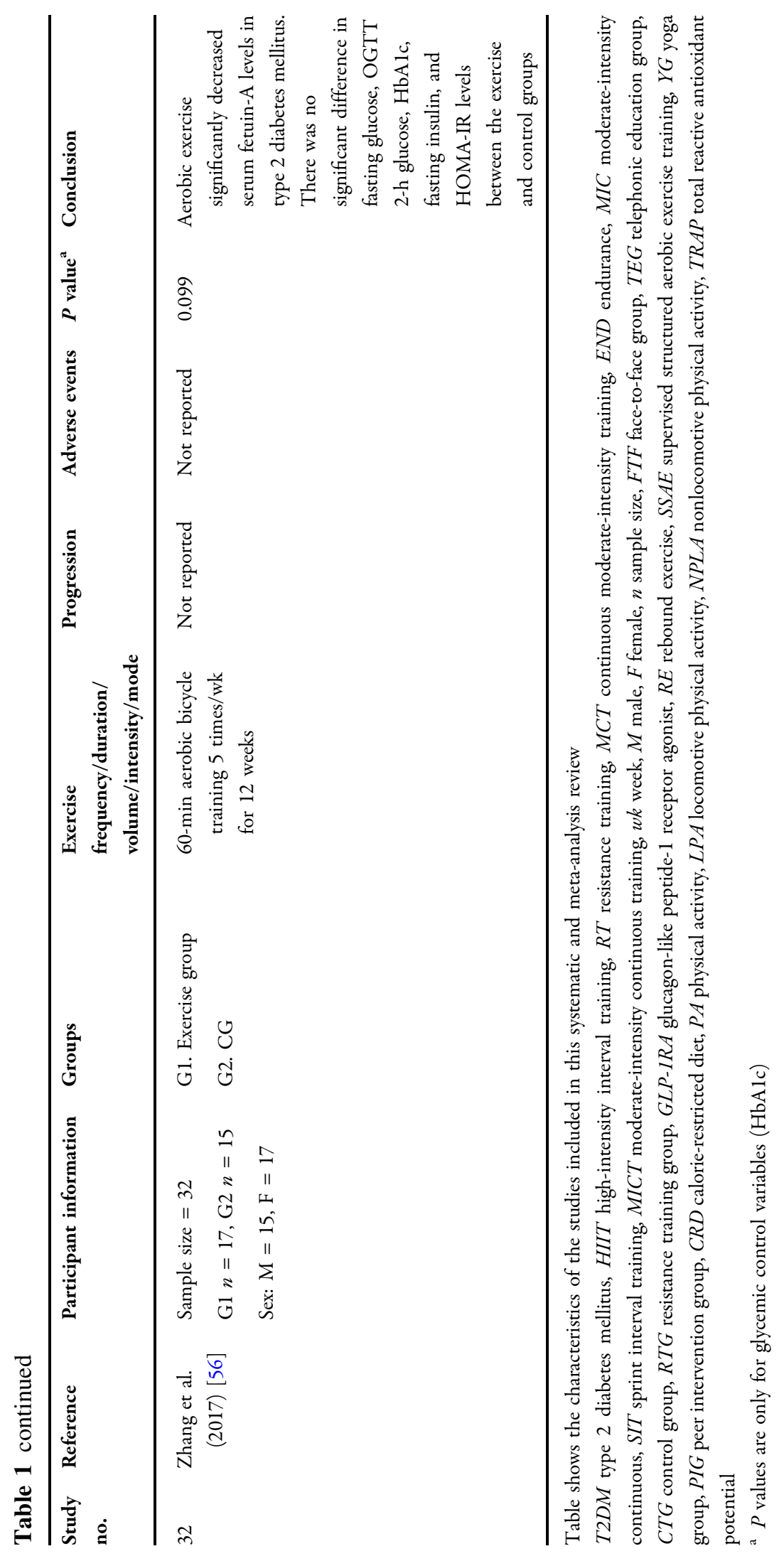


Random sequence generation (selection bias)

Allocation concealment (selection bias)

Blinding of participants and personnel (performance bias)

Blinding of the therapist (performance bias)

Blinding of outcome assessment (detection bias)

Deviation from intended intervention (Performance bias)

Incomplete outcome data (attrition bias)

Selective reporting (reporting bias)
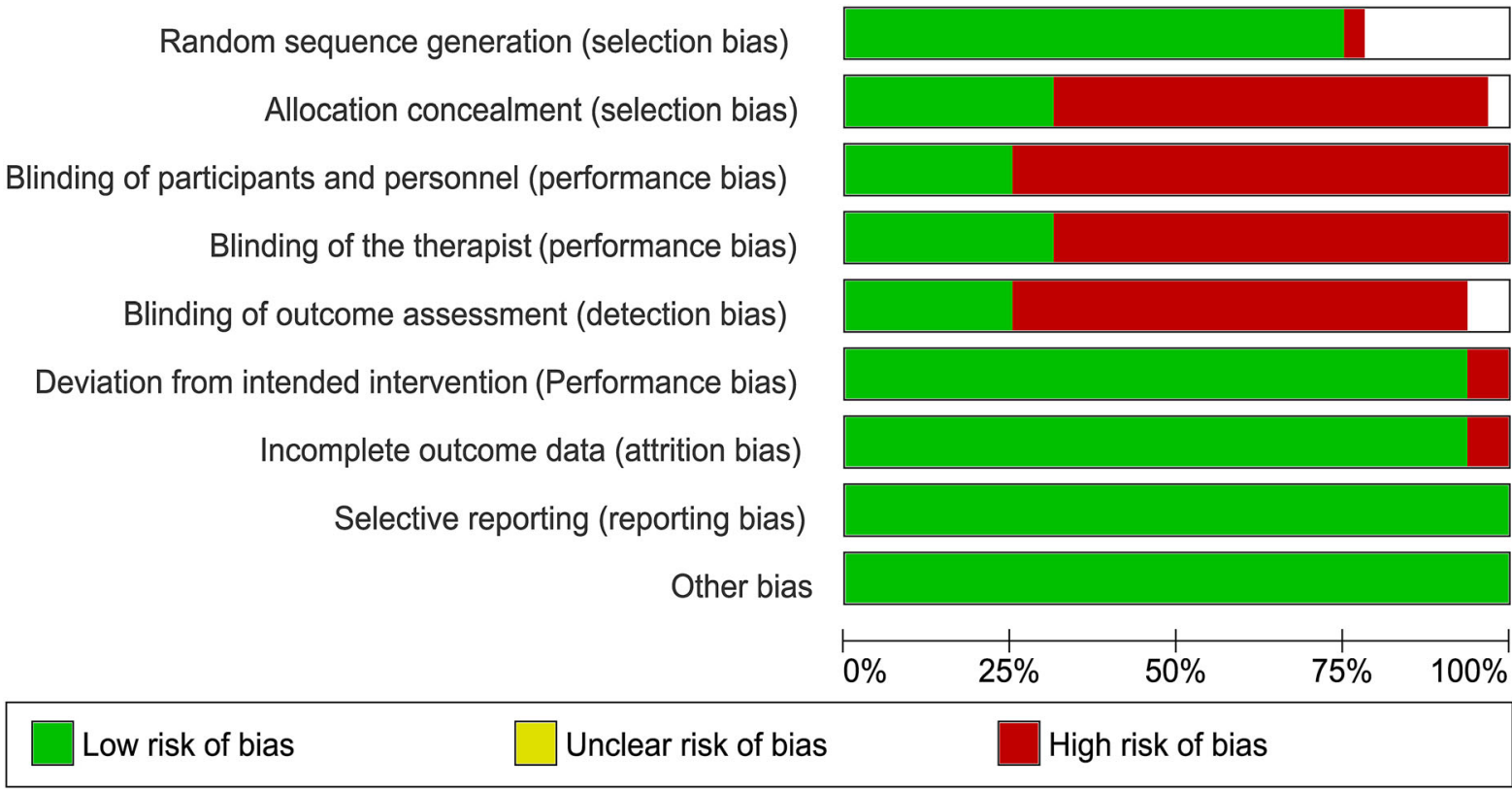

Fig. 2 Risk of bias graph. The review authors' judgments about each risk of bias item are presented as percentages across all included studies

\section{META-ANALYSIS}

\section{Outcomes}

\section{Effects of Exercise Intervention on Glycemic Control}

Postexercise Improvements in Glycated Hemoglobin (HbA1c) A total of 26 studies were analyzed in this segment. There were significant differences between the exercise and control groups regarding HbA1c improvement after exercise intervention (Fig. $4 \mathrm{a}, \quad P<0.0001$, $\left.Z=4.28, I^{2}=81 \%\right)[26-34,37-42,44,46-49$, $51,53,54,56,57,60]$. Similarly, when the four studies [29, 32, 38, 49] with no nonexercise groups were excluded, significant improvements in HbA1c were observed after exercise intervention (Fig. 4b, $P<0.0001, \quad Z=3.81$, $\left.I^{2}=83 \%\right)$.

\section{Postexercise Improvements in Fasting Blood} Glucose (FBG) Fasting blood glucose was reported by 13 studies. Analysis of FBG showed a significant difference between the exercise and nonexercise groups (Fig. 4c, $P=0.03$,
$\left.Z=2.21, I^{2}=99 \%\right)[26,27,34,35,37,42,44$, $47,48,51,56,57]$.

\section{Anthropometric Changes}

Effect of Exercise Intervention on Body Mass Index (BMI) A comparison of 13 studies that reported BMI changes after exercise intervention showed that BMI improved significantly with exercise (Fig. 5a, $P=0.04, \quad Z=2.04$, $\left.I^{2}=91 \%\right)[26,29,30,34,35,41,44,47,51,54$, $56,57,60]$.

Effect of Exercise Intervention on Body Weight A total of 11 studies were analyzed to assess the weight reduction after exercise intervention. No significant improvement in weight reduction was achieved following exercise intervention, according to random-effects models (Fig. 5b, $P=0.11, Z=1.60, I^{2}=78 \%$ ), but significant improvement was seen with a fixed-effects model $(P=0.02)[26,29,31,33$, $35,42,44,48,54,56,57]$.

Effect of Exercise Intervention on Waist Circumference Ten studies reported waist circumference changes following exercise 


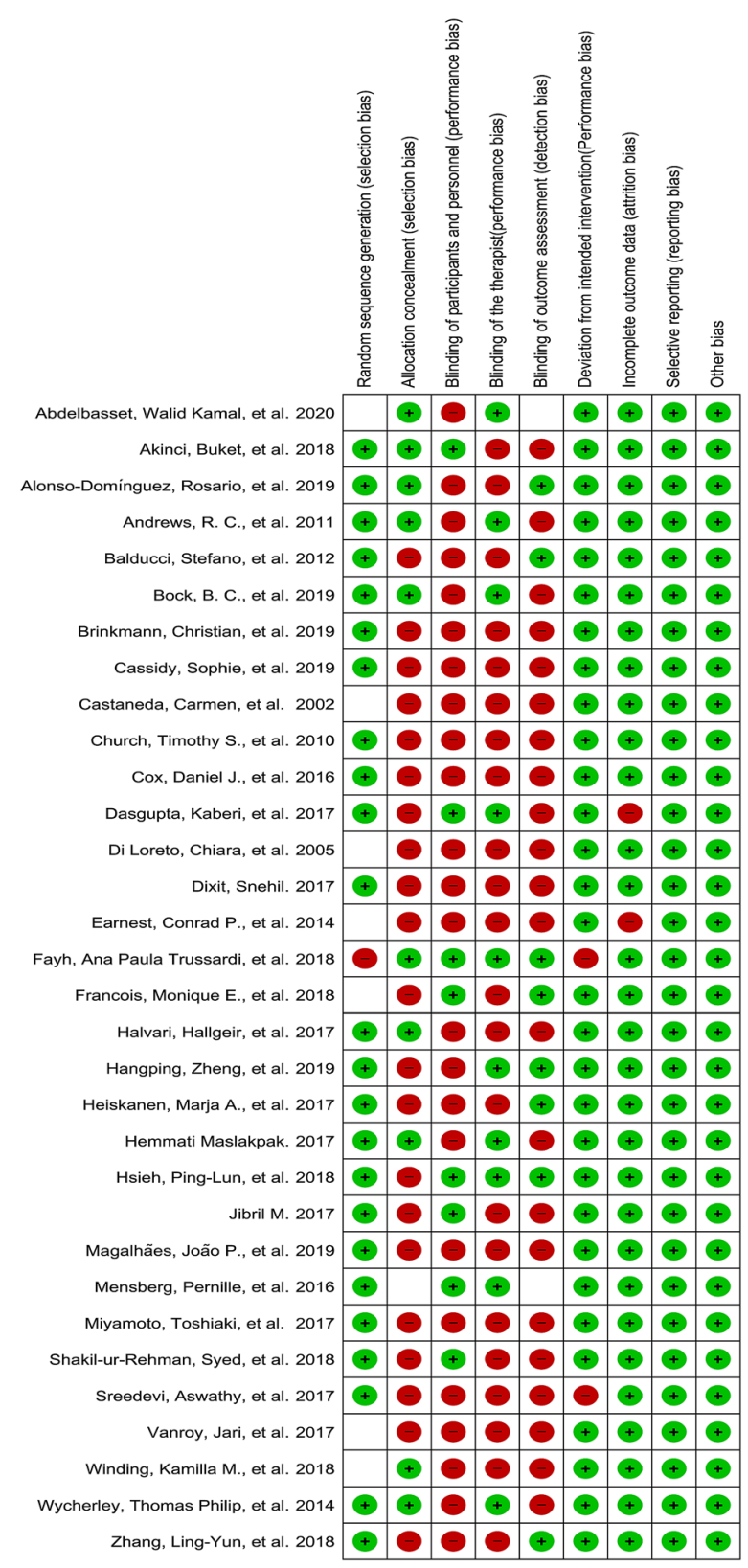

Fig. 3 Risk of bias summary table that presents the authors' judgments about each risk of bias item for each included study

intervention. A significant difference was observed among the studies regarding improvement in waist circumference after exercise intervention (Fig. 5c, $P=0.007$,
$\left.Z=2.71, I^{2}=91 \%\right) \quad[26,29,33,35,41,44$, $47,48,53,56]$.

\section{DISCUSSION}

This systematic review and meta-analysis aimed to quantitatively examine the evidence regarding the therapeutic effects of exercise and general physical activity on glycemic control, exercise-associated anthropometric changes, and QoL in type $2 \mathrm{DM}$ patients. Thirty-two studies with 2140 participants who underwent a wide variety of exercise interventions were included in this systematic review and metaanalysis. The main findings of this study are that various types of exercise can improve glycemic control and quality of life and can induce significant anthropometric changes in type 2 DM patients.

\section{Glycemic Control}

Our meta-analysis of 26 studies [26-31, 33, 34, $38-42,44,46-49,51,53,54,56,57,60]$ that reported patient $\mathrm{HbA1c}$ levels revealed that exercise intervention significantly improved patient HbA1c levels. However, these findings could be limited by variation in the HbA1c level set as an enrollment criterion in the included studies. This enrollment criterion was either HbA1c $\geq 6.5$ [27, 43-45], HbA1c 7-10 [34], HbA1c 6.4-7 [26, 30, 32, 37-44], HbA1c 7.2-9 [28, 31, 33, 47], HbA1c 10-11 [36, 48, 49], or HbA1c 6.5-11 [27, 36, 45]. We can assume that there is a greater chance of a decrease in HbA1c in a population with higher HbA1c levels than in a population with lower HbA1c levels. Similarly, a significant reduction in FBG was observed in this study, further verifying the therapeutic efficacy of exercise.

\section{Anthropometric Changes}

In this study, significant improvements in BMI $[26,29,30,34,35,41,44,47,50,51,54,56,57]$ and waist circumference $[26,29,33,35,41,44$, $47,48,53,56]$ were observed with exercise intervention. These anthropometric changes 
724

Diabetes Ther (2021) 12:707-732

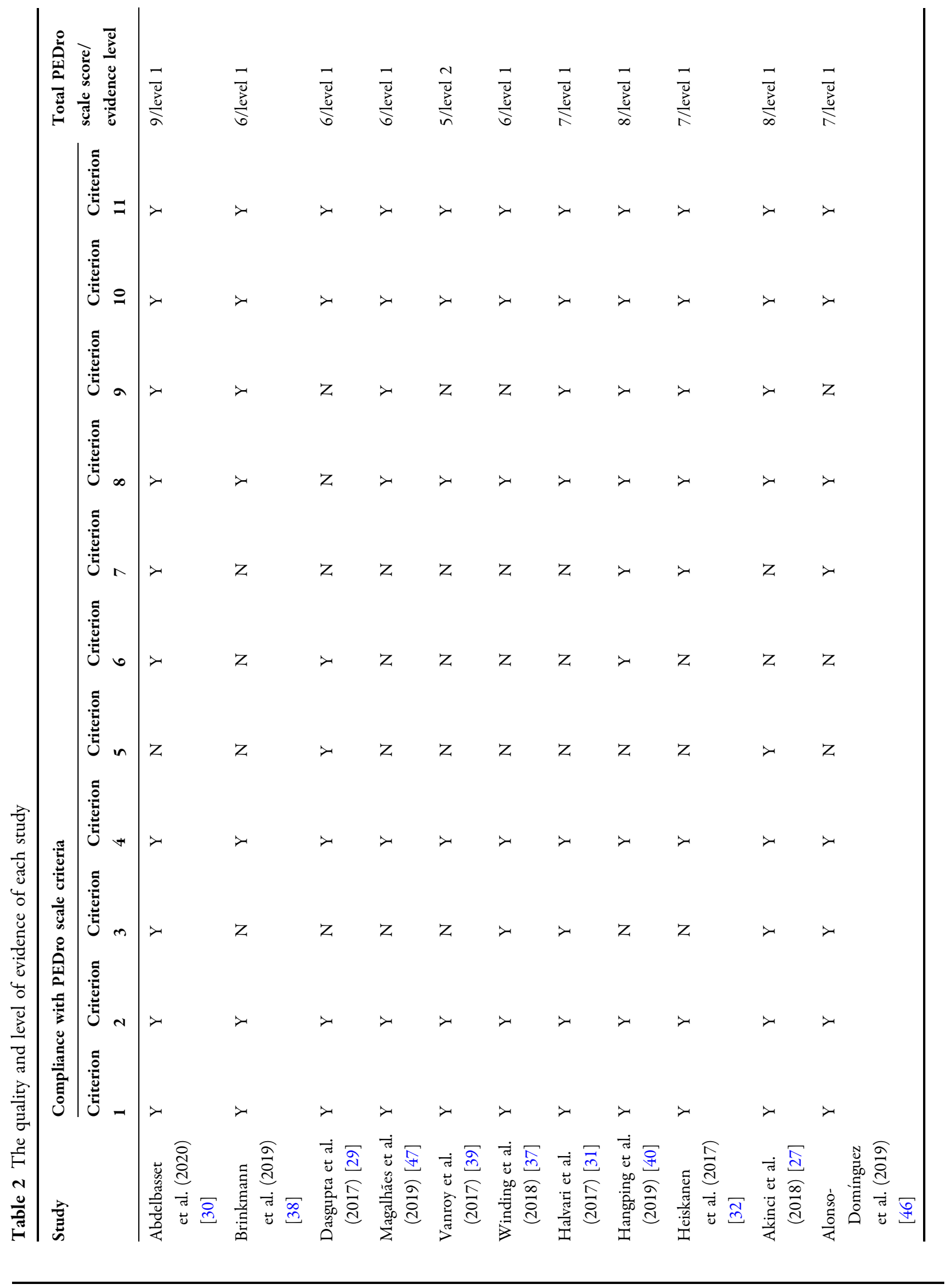

$\triangle$ Adis 


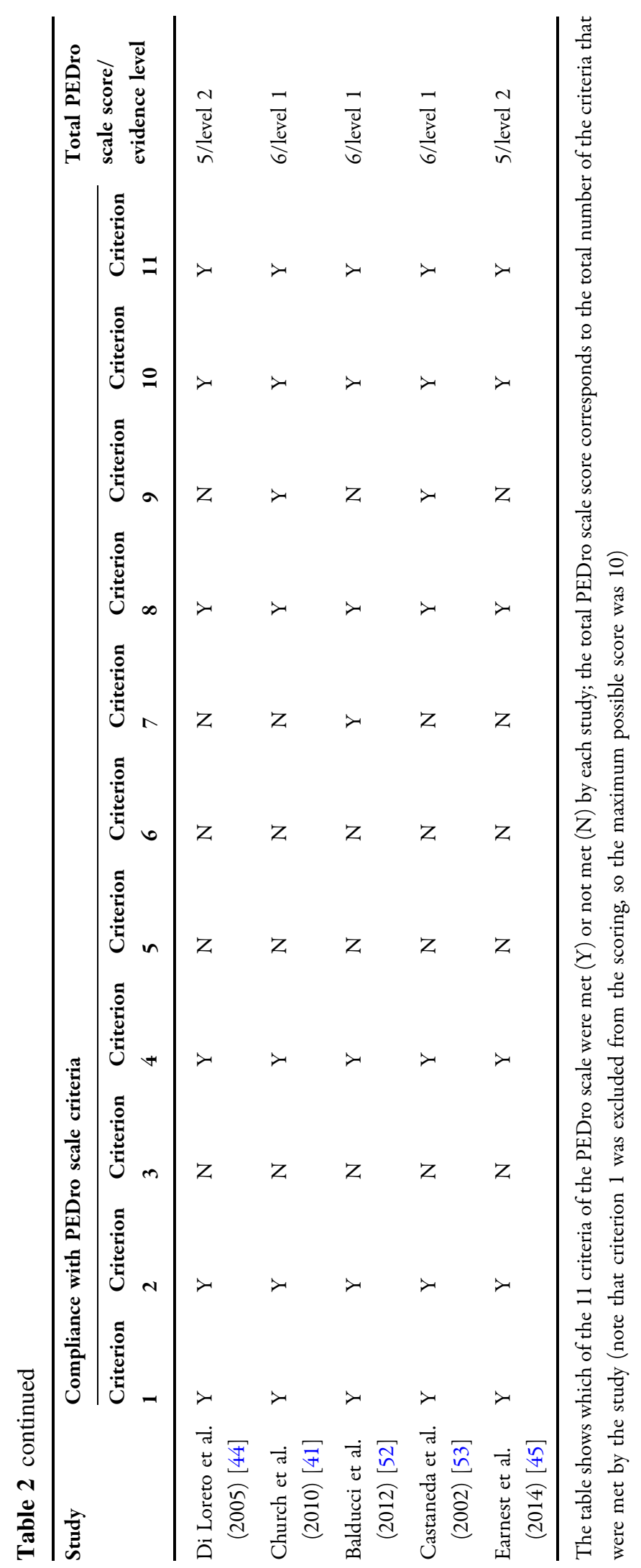




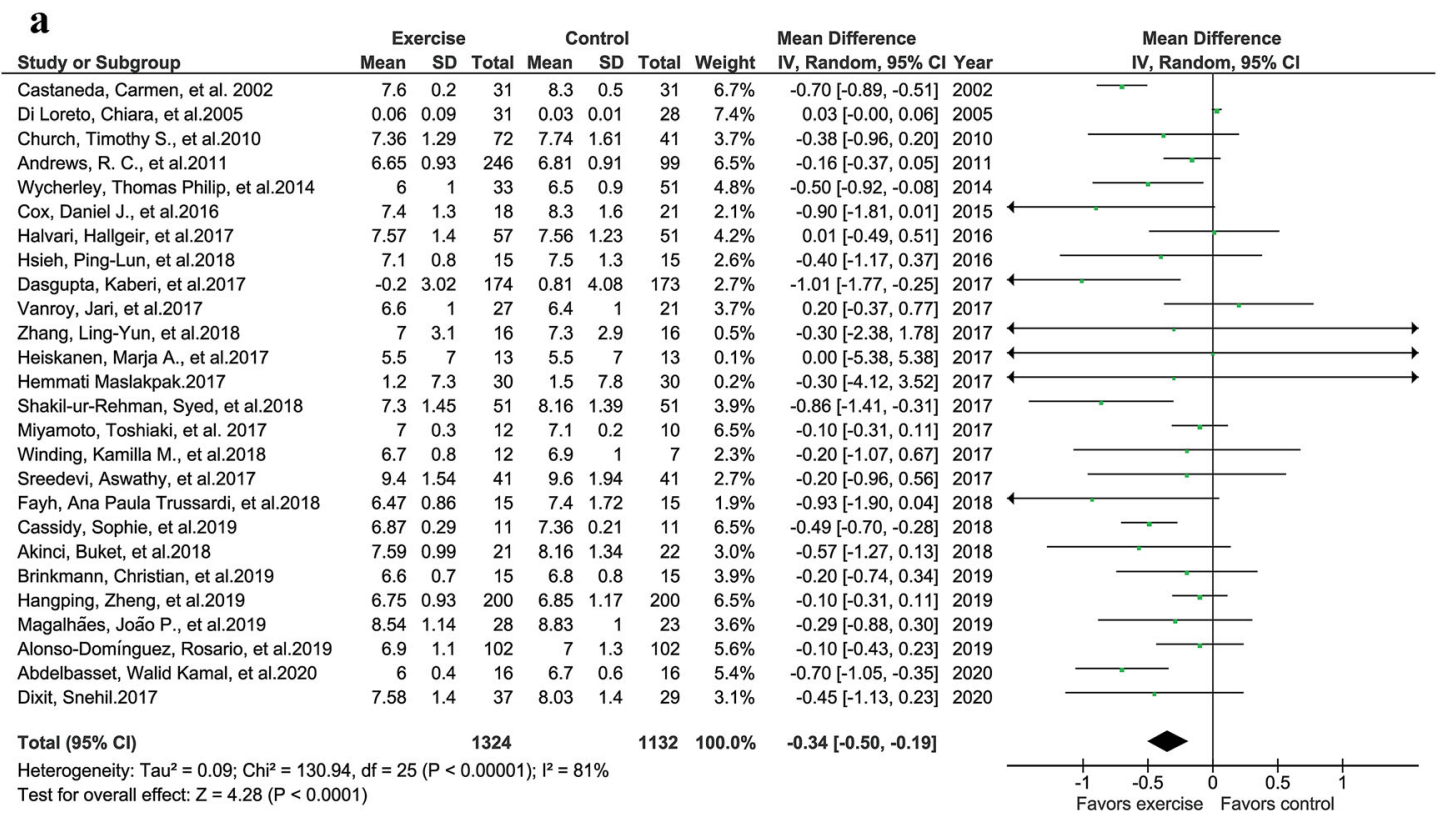

b

Study or Subgroup

Castaneda, Carmen, et al. 2002

Di Loreto, Chiara, et al.2005

Church, Timothy S., et al.2010

Andrews, R. C., et al.2011

Wycherley, Thomas Philip, et al.2014

Cox, Daniel J., et al.2016

Halvari, Hallgeir, et al.2017

Hsieh, Ping-Lun, et al.2018

Sreedevi, Aswathy, et al.2017

Vanroy, Jari, et al.2017

Zhang, Ling-Yun, et al.2018

Hemmati Maslakpak.2017

Shakil-ur-Rehman, Syed, et al.2018

Miyamoto, Toshiaki, et al. 2017

Winding, Kamilla M., et al.2018

Akinci, Buket, et al.2018

Cassidy, Sophie, et al.2019

Alonso-Domínguez, Rosario, et al.2019

Hangping, Zheng, et al.2019

Magalhães, João P., et al.2019

Dixit, Snehil.2017

Abdelbasset, Walid Kamal, et al.2020

Exercise Control(Non-exercise)

Mean Difference

Mean Difference

7.0an SD Total Mean SD Total Weight IV, Random, 95\% Cl Yea

$\begin{array}{lllllllll}7.6 & 0.2 & 31 & 8.3 & 0.5 & 31 & 7.3 \% & -0.70[-0.89,-0.51] 2002\end{array}$

$\begin{array}{lllllllll}0.06 & 0.09 & 31 & 0.03 & 0.01 & 28 & 8.1 \% & 0.03[-0.00,0.06] 2005\end{array}$

$\begin{array}{lllllllll}7.36 & 1.29 & 72 & 7.74 & 1.61 & 41 & 4.0 \% & -0.38[-0.96,0.20] & 2010\end{array}$

$\begin{array}{llllllll}6.65 & 0.93 & 246 & 6.81 & 0.91 & 99 & 7.1 \% & -0.16[-0.37,0.05] \\ 2011\end{array}$

$\begin{array}{lllllllll}6 & 1 & 33 & 6.5 & 0.9 & 51 & 5.3 \% & -0.50[-0.92,-0.08] & 2014\end{array}$

$\begin{array}{rrrrrrrr}7.4 & 1.3 & 18 & 8.3 & 1.6 & 21 & 2.3 \% & -0.90[-1.81,0.01] 2015\end{array}$

$\begin{array}{rrrrrrrr}7.57 & 1.4 & 57 & 7.56 & 1.23 & 51 & 4.6 \% & 0.01[-0.49,0.51] 2016\end{array}$

$\begin{array}{rrrrrrrr}7.1 & 0.8 & 15 & 7.5 & 1.3 & 15 & 2.9 \% & -0.40[-1.17,0.37] 2016\end{array}$

$\begin{array}{llllllll}9.4 & 1.54 & 41 & 9.6 & 1.94 & 41 & 2.9 \% & -0.20[-0.96,0.56] 2017\end{array}$

$\begin{array}{lllllllll}6.6 & 1 & 27 & 6.4 & 1 & 21 & 4.1 \% & 0.20[-0.37,0.77] 2017\end{array}$

$\begin{array}{rrrrrrr}7 & 3.1 & 16 & 7.3 & 2.9 & 16 & 0.6 \%\end{array}$

$\begin{array}{lllllll}1.2 & 7.3 & 30 & 1.5 & 7.8 & 30 & 0.2 \%\end{array}$

$\begin{array}{lllllll}7.3 & 1.45 & 51 & 8.16 & 1.39 & 51 & 4.2 \%\end{array}$

$\begin{array}{lllllll}7 & 0.3 & 12 & 7.1 & 0.2 & 10 & 7.2 \%\end{array}$

$\begin{array}{rrrrrrr}6.7 & 0.8 & 12 & 6.9 & 1 & 7 & 2.4 \%\end{array}$

$\begin{array}{lllllll}7.59 & 0.99 & 21 & 8.16 & 1.34 & 22 & 3.2 \%\end{array}$

$\begin{array}{lllllll}6.87 & 0.29 & 11 & 7.36 & 0.21 & 11 & 7.2 \%\end{array}$

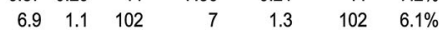

$\begin{array}{lllllll}6.75 & 0.93 & 200 & 6.85 & 1.17 & 200 & 7.2 \%\end{array}$

$\begin{array}{lllllll}8.54 & 1.14 & 28 & 8.83 & 1 & 23 & 3.9 \%\end{array}$

$\begin{array}{lllllll}7.58 & 1.4 & 37 & 8.03 & 1.4 & 29 & 3.3 \%\end{array}$

$\begin{array}{lllr}6 & 0.4 & 16 & 6.7\end{array}$

$0.20[-0.37,0.77]$
$-0.30[-2.38,1.78]$
2017

$-0.30[-4.12,3.52] 2017$

$-0.86[-1.41,-0.31] 2017$

$-0.10[-0.31,0.11] 2017$

$-0.20[-1.07,0.67] 2017$

$-0.57[-1.27,0.13] 2018$

$-0.49[-0.70,-0.28] 2018$

$-0.10[-0.43,0.23] 2019$

$-0.10[-0.31,0.11] 2019$

$-0.29[-0.88,0.30] 2019$

$-0.45[-1.13,0.23] 2020$

$\begin{array}{rr}-0.45[-1.13,0.23] & 2020 \\ -0.70[-1.05,-0.35] & 2020\end{array}$

Total $(95 \% \mathrm{Cl})$

1107

$916 \quad 100.0 \% \quad-0.32[-0.48,-0.15]$

Heterogeneity: Tau $^{2}=0.08 ; \mathrm{Ch}^{2}=120.68, \mathrm{df}=21(\mathrm{P}<0.00001) ; \mathrm{I}^{2}=83 \%$

Test for overall effect: $Z=3.81(P=0.0001)$

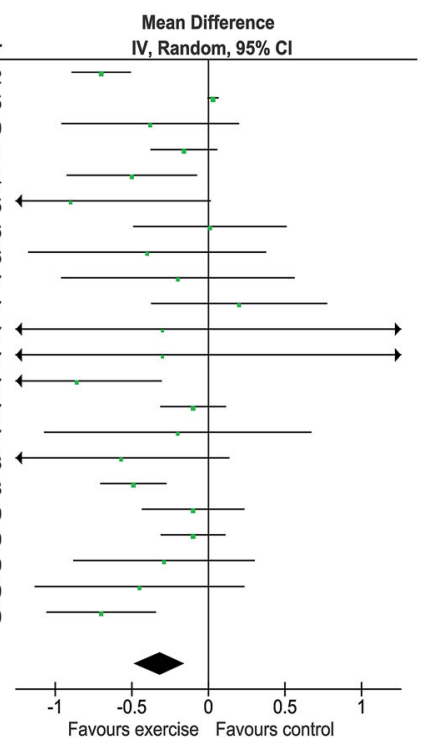

C

Study or Subgroup

Exercise Control

Di Loreto, Chiara, et al.2005

Andrews, R. C., et al.2011

Hsieh, Ping-Lun, et al.2018

Winding, Kamilla M., et al.2018

Shakil-ur-Rehman, Syed, et al.2018

Miyamoto, Toshiaki, et al. 2017

Sreedevi, Aswathy, et al.2017

Zhang, Ling-Yun, et al.2018

Hemmati Maslakpak.2017

Akinci, Buket, et al.2018

Jibril M.2017

Cassidy, Sophie, et al.2019

Magalhães, João P., et al.2019

\begin{tabular}{rrrrr}
\multicolumn{3}{c}{ Exercise } & \multicolumn{2}{c}{ Control } \\
Mean & SD & Total & Mean & SD \\
-0.2 & 0.3 & 31 & 1.6 & 2.9 \\
1.99 & 0.2 & 246 & 2.04 & 0.27 \\
6.78 & 0.85 & 15 & 7.78 & 3.38 \\
8 & 1.5 & 12 & 9.4 & 2.1 \\
252.1 & 27.11 & 51 & 279.36 & 33.31 \\
137.8 & 6.2 & 12 & 140.7 & 9.4 \\
159.5 & 44.08 & 41 & 181.84 & 71.77 \\
6.5 & 2.1 & 16 & 6.8 & 2.6 \\
33.43 & 138.33 & 30 & 38.69 & 150.9 \\
130.59 & 41 & 22 & 17.27 & 68.47 \\
7.05 & 0.2825 & 30 & 9 & 0.0001 \\
116.41 & 23.71 & 37 & 141.58 & 44.46 \\
8.3 & 2.5 & 22 & 8.4 & 3.6 \\
& & & &
\end{tabular}

Total $(95 \% \mathrm{Cl})$

Heterogeneity: $\mathrm{Tau}^{2}=1.89 ; \mathrm{Chi}^{2}=1096.04, \mathrm{df}=12(\mathrm{P}<0.00001) ; \mathrm{I}^{2}=99 \%$

Test for overall effect: $Z=2.21(P=0.03)$

Mean Difference Mean Difference Whal Weight Random, 95\% Cl Year

$28 \quad 14.8 \% \quad-1.80[-2.88,-0.72] 2005$

$99 \quad 17.2 \% \quad-0.05[-0.11,0.01] 2011$

$15 \quad 12.0 \% \quad-1.00[-2.76,0.76] 2016$

$7 \quad 12.0 \%$

$51 \quad 0.9 \%$

$10 \quad 2.3 \%$

$41 \quad 0.2 \%$

$16 \quad 12.6 \%$

$30 \quad 0.0 \%$

$22 \quad 0.1 \%$

$30 \quad 17.2 \%$

$29 \quad 0.4 \%$

$13 \quad 10.3 \%$

$391 \quad 100.0 \%$

-1.40[-3.17, 0.37] 2017

$-2.90[-9.70,3.90] 2017$

$-22.34[-48.12,3.44] 2017$

$-0.30[-1.94,1.34] 2017$

$-5.26[-78.51,67.99] 2017$

3.32 [79.97, 146.67] 2018

$-1.95[-2.05,-1.85] 2018$

$-0.10[-2.32,2.12] 2019$

$-1.26[-2.38,-0.14]$

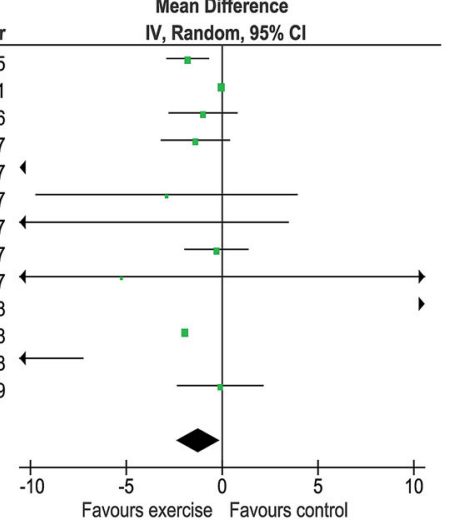


4Fig. 4 Glycemic control. a HbAlc exercise vs control groups. b HbAlc exercise vs nonexercise control groups. c Fasting blood glucose (FBG) exercise vs control groups

could maximize the wellbeing of diabetes patients and reduce the likelihood of obesity- or weight-gain-associated complications. Most of the studies reported a decrease in body weight after the intervention; however, the findings of the meta-analysis were nonsignificant. We hypothesize that weight reduction needs vigorous exercises and long-term follow-up.

\section{Quality of Life}

Exercise improves wellbeing and enhances the quality of life. Two studies showed that exercise led to improved psychological functioning [33], significant improvements in overall QoL, sexuality, mobility, anxiety and worry, diabetes control, and severity, and no significant change

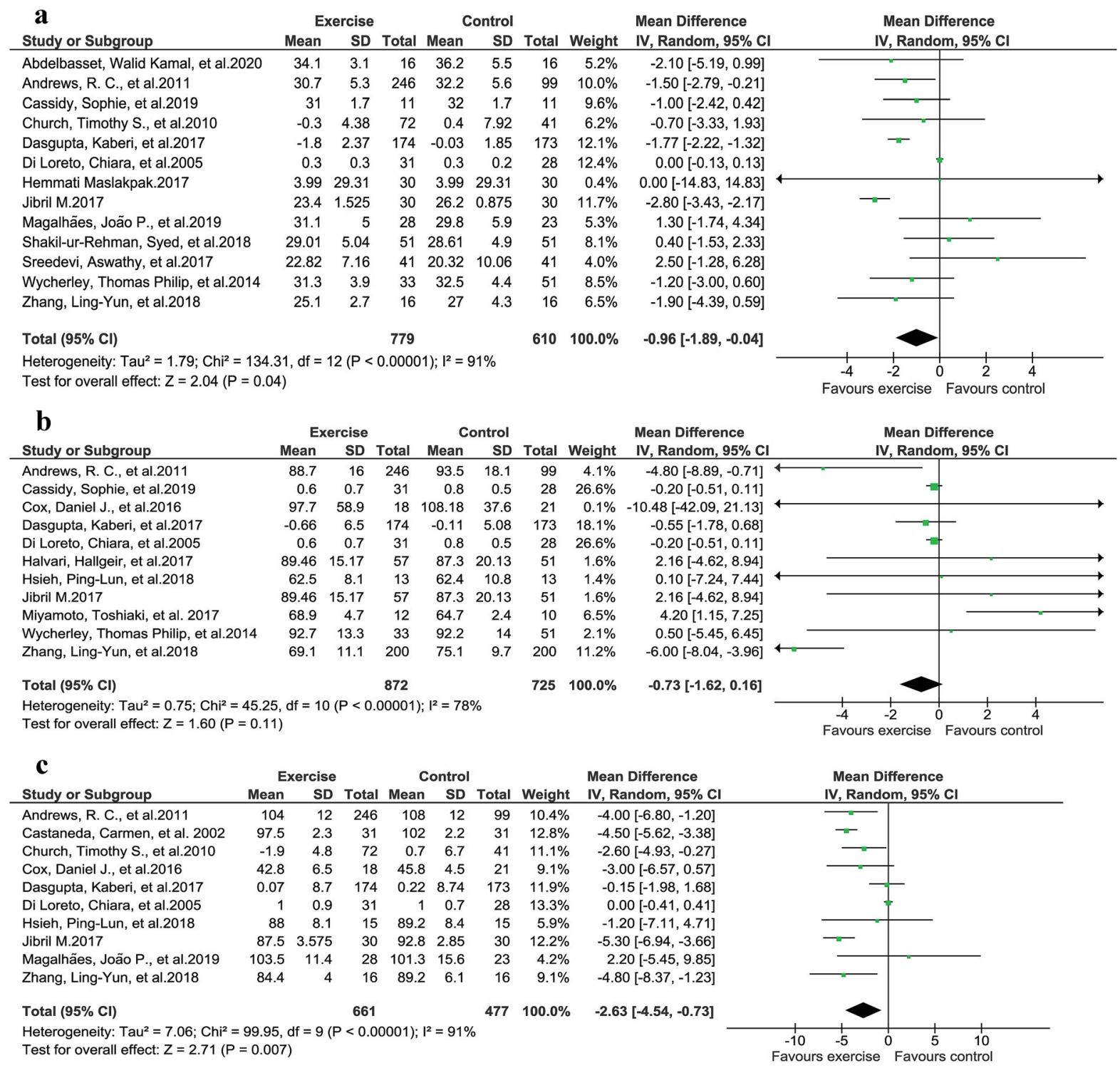

Fig. 5 Anthropometric changes due to exercise intervention. a Improvements in BMI (body mass index). b Improvements in body weight. $\mathbf{c}$ Reduction in waist circumference 
in the social burden domain (D-39) [54]. A study reported similar increases in QoL in two groups, one receiving liraglutide and exercise intervention and the other receiving placebo and exercise intervention. Despite some liraglutide treatment-associated side effects, the QoL in the exercise plus liraglutide group was not inferior. These findings indicate the importance of exercise in improving QoL [36]. Another study reported that yoga led to a greater increase in QoL than standard exercise, but there was no significant between-group difference in QoL [43]. One study reported that the change in QoL following exercise intervention was nonsignificant; it was argued that this result was obtained because the QoL questionnaire-the Audit of Diabetes Dependent Quality of Life (ADDQoL) - may not have been appropriate for the population studied [48]. However, only three of the studies that reported QoL had a nonexercise group. When the study only compares exercise groups, all of the participants may undergo similar improvements in QoL. A comparison between nonexercise and exercise groups could offer greater insight into the effects of exercise on QoL [33, 48, 54].

\section{Different Exercise Regimens and Their Effects on Blood Sugar and Body Composition}

\section{Nutrition Plus Exercise}

Interestingly, it was observed that nutritional status (fasted overnight or fed) is not an important factor in exercise interventions to improve glycemic control in type $2 \mathrm{DM}$ patients [38]. Diet plus exercise leads to a significant weight reduction [54]; moreover, glucose levels can be strongly controlled by following an intensive diet plan after being diagnosed with type $2 \mathrm{DM}$, such that the addition of physical activity (PA) may produce no additional benefits [26]. The GEM (glycemic load, exercise, and monitoring blood glucose) program is unique and effective at modifying lifestyle and controlling HbA1c in diabetic patients [33].

\section{Anaerobic Training}

Evidence has shown that HIIT significantly improves glycemic control (HbA1c) [30, 55, 57] and BMI [30]. Unsupervised HIIT [57] and HIIT even in lower training volume than endurance exercise, has better effects than endurance exercise on fitness and glycemic control [37]. However, one study reported that SIT may be less beneficial for a diabetic heart than MICT, but MICT may reduce the HbA1c level more than SIT [32]. Another study added that HIIT with RT did not affect glycemic control; however, a year of combined MCIT and RT intervention improved body composition [47].

\section{Aerobic Training}

Aerobic exercise plays a key role in optimizing blood glucose and inducing anthropometric changes. Different types of aerobic training have been shown to be effective in type $2 \mathrm{DM}$ patients. MICT significantly improves HbA1c $[28,30,56]$, BMI [30], and body composition [47], and assists with weight loss [56]. Supervised structured aerobic exercise training (SSAET) is effective at reducing BMI, FBG, and HbA1c [51]. Additionally, a study reported that the full benefits of aerobic exercise could be achieved with an energy expenditure of more than $20 \mathrm{METs} / \mathrm{hr} /$ week [44].

\section{Resistance Training}

Resistance exercises are of paramount importance to weight loss and glycemic control. Studies included in this review revealed significant glycemic control and anthropometric changes [48] with resistance training (RT) interventions such as bioDensity resistance training [59], progressive resistance training (PRT) [53], and supervised and structured RT [48].

\section{Combined Exercise Training}

Combining different exercise regimens could result in additional benefits. A combined aerobic and RT approach was found to be better for HbA1c control than aerobic or resistance training alone [41]. Moreover, aerobic and resistance training with exercise counseling significantly improved fitness, HbA1c, and weight loss [52]. 
Supervised RT with HIIT exercise training and liraglutide induced major improvements in glycemic control along with robust weight loss [36]. Another study showed that a year of MCT with RT improved body composition [47].

\section{Yoga}

A limited number of studies used yoga as an intervention for type 2 DM. Findings regarding the effects of yoga on glycemic control are not conclusive due to the limited number of studies that included yoga. In one of the studies, yoga significantly improved HbA1c as compared to standard exercise [43], while it had incremental effects on glycemic control in another study [34]. Long-term studies of the benefit of yoga in type $2 \mathrm{DM}$ are warranted.

\section{Walking and Physical Activity (PA)}

General physical activity is generally considered to be of less value than exercise intervention when it comes to weight loss and glycemic control in type $2 \mathrm{DM}$ patients. However, the findings of the studies in the present review in relation to general physical activity are interesting, with most of them showing that such activity improved glycemic control [29, 31, 39]. Miyamoto et al. reported that nonlocomotive physical activity (N-LPA) did not affect glucose and fat levels [42].

A study reported that rebound exercise could be beneficial in type $2 \mathrm{DM}$ [35]. Moreover, a supervised group-based or Internet-based exercise is more beneficial than simple counseling for achieving glycemic control, reducing the waist circumference, and improving quality of life [27].

\section{Limitations}

A limitation of this study is the inability to group the findings of different studies according to the exercise regimes used, such as resistance training, aerobic training, high-intensity interval training, and moderate-intensity continuous training. An ability to group the findings in this manner would provide readers with a better understating of the effects of a variety of exercise regimens. However, we have partly mitigated this limitation by discussing each exercise regimen separately.

\section{CONCLUSIONS}

Exercise is the cornerstone to good Glycemic control in type $2 \mathrm{DM}$ patients. Exercise training can lead to significant anthropometric changes and enhance the quality of life. An exercise plan involving 40 - to 60 -min sessions 3-5 days per week or $150 \mathrm{~min}$ of exercise per week can significantly improve glycemic control, BMI, and waist circumference. However, according to our findings, structured exercise performed as rarely as 1-2 days per week can also reduce blood glucose. Although considered to be less intense activities, general physical activity and walking could still help to reduce blood glucose.

\section{ACKNOWLEDGEMENTS}

Funding. No funding or sponsorship was received for this study or the publication of this article. The Rapid Service Fee was funded by the authors.

Authorship. All named authors meet the International Committee of Medical Journal Editors (ICMJE) criteria for authorship for this article, take responsibility for the integrity of the work as a whole, and have given their approval for this version to be published.

Disclosures. Sayed Zulfiqar Ali Shah, Jawad Alam Karam, Alam Zeb, Rafi Ullah, Arif Shah, Ijaz Ul Haq, Iftikhar Ali, Haider Darain, and Hong Chen declare that they have no conflict of interest.

Compliance with Ethics Guidelines. This article is based on previously conducted studies and does not contain any studies with human participants or animals performed by any of the authors.

Data Availability. All data for this article are presented in this manuscript. 
Open Access. This article is licensed under a Creative Commons Attribution-NonCommercial 4.0 International License, which permits any non-commercial use, sharing, adaptation, distribution and reproduction in any medium or format, as long as you give appropriate credit to the original author(s) and the source, provide a link to the Creative Commons licence, and indicate if changes were made. The images or other third party material in this article are included in the article's Creative Commons licence, unless indicated otherwise in a credit line to the material. If material is not included in the article's Creative Commons licence and your intended use is not permitted by statutory regulation or exceeds the permitted use, you will need to obtain permission directly from the copyright holder. To view a copy of this licence, visit http:// creativecommons.org/licenses/by-nc/4.0/.

\section{REFERENCES}

1. Ijaz S, Ajmal M. Experiencing type II diabetes in Pakistan. Pak J Social Clin Psychol. 2011;9(1).

2. Sazlina S-G, Browning CJ, Yasin S. Promoting physical activity in sedentary elderly Malays with type 2 diabetes: a protocol for randomised controlled trial. BMJ Open. 2012;2(6):e002119.

3. Taylor JD, Fletcher JP, Tiarks J. Impact of physical therapist-directed exercise counseling combined with fitness center-based exercise training on muscular strength and exercise capacity in people with type 2 diabetes: a randomized clinical trial. Phys Ther. 2009;89(9):884-92.

4. International Diabetes Federation. IDF diabetes atlas, 9th edn. Brussels: IDF; 2019. https://www. diabetesatlas.org

5. Short KR, Vittone JL, Bigelow ML, et al. Impact of aerobic exercise training on age-related changes in insulin sensitivity and muscle oxidative capacity. Diabetes. 2003;52(8):1888-96.

6. Khan I, King H. Pakistan National Diabetes Survey prevalence of glucose intolerance and associated factors in North West Frontier Province (NVVFP) of Pakistan. JPMA. 1999;49:206.
7. Rosenbloom AL, Joe JR, Young RS, Winter WE. Emerging epidemic of type 2 diabetes in youth. Diabetes Care. 1999;22(2):345-54.

8. Iqbal T, Rashid F, Saleem SA, Shah SA, Khalid GH, Ishtiaq O. Awareness about diabetes mellitus amongst diabetics. JRMC. 2013;17(2):294-6.

9. Qidwai W, Ashfaq T. Imminent epidemic of diabetes mellitus in Pakistan: issues and challenges for health care providers. JLUMHS. 2010;9(3):112-3.

10. Akhter J. The burden of diabetes in Pakistan: the National Diabetes Survey. JPMA. 1999;49(9):205.

11. Hakeem R, Fawwad A. Diabetes in Pakistan: epidemiology, determinants and prevention. J Diabetol. 2010;1(3):3.

12. Anderson RM, Funnell MM, Arnold MS, Barr PA, Edwards GJ, Fitzgerald JT. Assessing the cultural relevance of an education program for urban African Americans with diabetes. Diabetes Educ. 2000;26(2):280-9.

13. Gabriel BM, Zierath JR. The limits of exercise physiology: from performance to health. Cell Metab. 2017;25(5):1000-11.

14. Sigal RJ, Kenny GP, Wasserman DH, CastanedaSceppa C, White RD. Physical activity/exercise and type 2 diabetes a consensus statement from the American Diabetes Association. Diabetes Care. 2006;29(6):1433-8.

15. Sigal RJ, Kenny GP, Wasserman DH, CastanedaSceppa C. Physical activity/exercise and type 2 diabetes. Diabetes Care. 2004;27(10):2518-39.

16. Sigal RJ, Kenny GP, Boulé NG, et al. Effects of aerobic training, resistance training, or both on glycemic control in type 2 diabetes: a randomized trial. Ann Intern Med. 2007;147(6):357-69.

17. Moher D, Liberati A, Tetzlaff J, Altman DG, PRISMA Group. Preferred reporting items for systematic reviews and meta-analyses: the PRISMA statement. PLoS Med. 2009;6(7):e1000097

18. Ouzzani M, Hammady H, Fedorowicz Z, Elmagarmid A. Rayyan-a web and mobile app for systematic reviews. Syst Rev. 2016;5(1):210.

19. Maher CG, Sherrington C, Herbert RD, Moseley AM, Elkins M. Reliability of the PEDro scale for rating quality of randomized controlled trials. Phy Ther. 2003;83:713-21.

20. Eng J, Teasell R, Miller W, et al. Spinal cord injury rehabilitation evidence: method of the SCIRE systematic review. Top Spinal Cord Inj Rehabil. 2007;13:1-10. 
21. Higgins JPT, Altman DG. Assessing risk of bias in included studies. In: Higgins JPT, Green S, editors. Cochrane handbook for systematic reviews of interventions. Chichester: Wiley; 2008. p. 187-241.

22. Cochrane Collaboration. Review Manager, version 5.3. Copenhagen: Cochrane Collaboration; 2014.

23. Hozo SP, Djulbegovic B, Hozo I. Estimating the mean and variance from the median, range, and the size of a sample. BMC Med Res Methodol. 2005;5(1):13.

24. Leppink J, O'Sullivan P, Winston K. Effect sizelarge, medium, and small. Perspectives Med Educ. 2016;5(6):347-9.

25. Lipsey MW, Wilson DB. Practical meta-analysis. Thousand Oaks: SAGE; 2001.

26. Andrews R, Cooper A, Montgomery A, et al. Diet or diet plus physical activity versus usual care in patients with newly diagnosed type 2 diabetes: the Early ACTID randomised controlled trial. The Lancet. 2011;378(9786):129-39.

27. Akinci B, Yeldan I, Satman I, Dirican A, Ozdincler AR. The effects of Internet-based exercise compared with supervised group exercise in people with type 2 diabetes: a randomized controlled study. Clin Rehabil. 2018;32(6):799-810. PubMed PMID: 29417832. eng.

28. Dixit S, Maiya A, Shastry B. Effect of moderate-intensity aerobic exercise on glycosylated haemoglobin among elderly patients with type 2 diabetes \& peripheral neuropathy. Indian J Med Res. 2017;145(1):129.

29. Dasgupta K, Rosenberg E, Joseph L, et al. Physician step prescription and monitoring to improve ARTERial health (SMARTER): A randomized controlled trial in patients with type 2 diabetes and hypertension. Diabetes Obes Metab. 2017;19(5): 695-704. PubMed PMID: 28074635.

30. Abdelbasset WK, Tantawy SA, Kamel DM, et al. Effects of high-intensity interval and moderate-intensity continuous aerobic exercise on diabetic obese patients with nonalcoholic fatty liver disease: a comparative randomized controlled trial. Medicine. 2020;99(10):e19471. PubMed PMID: 32150108 .

31. Halvari H, Healey J, Olafsen AH, et al. Physical activity and motivational predictors of changes in health behavior and health among DM2 and CAD patients. Scand J Med Sci Sports. 2017;27(11): 1454-69. PubMed PMID: 27688002.

32. Heiskanen MA, Sjöros TJ, Heinonen IH, et al. Sprint interval training decreases left-ventricular glucose uptake compared to moderate-intensity continuous training in subjects with type 2 diabetes or prediabetes. Sci Rep. 2017;7(1):1-11.

33. Cox DJ, Taylor AG, Singh H, et al. Glycemic load, exercise, and monitoring blood glucose (GEM): a paradigm shift in the treatment of type 2 diabetes mellitus. Diabetes Res Clin Pract. 2016;111:28-35.

34. Sreedevi A, Gopalakrishnan UA, Ramaiyer SK, Kamalamma L. A randomized controlled trial of the effect of yoga and peer support on glycaemic outcomes in women with type 2 diabetes mellitus: a feasibility study. BMC Complement Altern Med. 2017;17(1):100.

35. Nuhu JM, Maharaj SS. Influence of a mini-trampoline rebound exercise program on insulin resistance, lipid profile and central obesity in individuals with type 2 diabetes. J Sports Med Phys Fitness. 2017;58(4):503-9. PubMed PMID: 28249384.

36. Mensberg P, Nyby S, Jørgensen PG, et al. Nearnormalization of glycaemic control with glucagonlike peptide- 1 receptor agonist treatment combined with exercise in patients with type 2 diabetes. Diabetes Obes Metab. 2016;19(2):172-80. PubMed PMID: 27717126.

37. Winding KM, Munch GW, Iepsen UW, Van Hall G, Pedersen BK, Mortensen SP. The effect on glycaemic control of low-volume high-intensity interval training versus endurance training in individuals with type 2 diabetes. Diabetes Obes Metab. 2018;20(5):1131-9. PubMed PMID: 29272072.

38. Brinkmann C, Weh-Gray O, Brixius K, Bloch W, Predel HG, Kreutz T. Effects of exercising before breakfast on the health of T2DM patients-a randomized controlled trial. Scand J Med Sci Sports. 2019;29(12):1930-6. PubMed PMID: 31442336.

39. Vanroy J, Seghers J, Bogaerts A, Devloo K, De Cock $S$, Boen F. Short- and long-term effects of a needsupportive physical activity intervention among patients with type 2 diabetes mellitus: a randomized controlled pilot trial. PLoS One. 2017;12(4): e0174805. PubMed PMID: 28384237.

40. Hangping Z, Xiaona Q, Qi Z, et al. The impact on glycemic control through progressive resistance training with bioDensity ${ }^{\mathrm{TM}}$ in Chinese elderly patients with type 2 diabetes: the PReTTy2 (Progressive Resistance Training in Type 2 Diabetes) trial. Diabetes Res Clin Pract. 2019;150:64-71.

41. Church TS, Blair SN, Cocreham S, et al. Effects of aerobic and resistance training on hemoglobin A1c levels in patients with type 2 diabetes: a randomized controlled trial. JAMA. 2010;304(20):2253-62. 
42. Miyamoto T, Fukuda K, Oshima Y, Moritani T. Nonlocomotive physical activity intervention using a tri-axial accelerometer reduces sedentary time in type 2 diabetes. Phys Sportsmed. 2017;45(3): 245-51. PubMed PMID: 28664755.

43. Bock BC, Thind H, Fava JL, et al. Feasibility of yoga as a complementary therapy for patients with type 2 diabetes: the Healthy Active and in Control (HA1C) study. Complement Ther Med. 2019.42: 125-31. PubMed PMID: 30670230.

44. Di Loreto C, Fanelli C, Lucidi P, et al. Make your diabetic patients walk: long-term impact of different amounts of physical activity on type 2 diabetes. Diabetes Care. 2005;28(6):1295-302.

45. Earnest CP, Johannsen NM, Swift DL, et al. Aerobic and strength training in concomitant metabolic syndrome and type 2 diabetes. Med Sci Sports Exerc. 2014;46(7):1293.

46. Alonso-Domínguez R, García-Ortiz L, PatinoAlonso MC, et al. Effectiveness of a multifactorial intervention in increasing adherence to the Mediterranean diet among patients with diabetes mellitus type 2: a controlled and randomized study (EMID study). Nutrients. 2019;11(1):162.

47. Magalhães JP, Júdice PB, Ribeiro R, et al. Effectiveness of high-intensity interval training combined with resistance training versus continuous moderate-intensity training combined with resistance training in patients with type 2 diabetes: a one-year randomized controlled trial. Diabetes Obes Metab. 2019;21(3):550-9. PubMed PMID: 30284352.

48. Hsieh P-L, Tseng C-H, Tseng YJ, Yang W-S. Resistance training improves muscle function and cardiometabolic risks but not quality of life in older people with type 2 diabetes mellitus: a randomized controlled trial. J Geriatr Phys Ther. 2018;41(2): 65-76.

49. Fayh APT, Borges K, Cunha GS, et al. Effects of n-3 fatty acids and exercise on oxidative stress parameters in type 2 diabetic: a randomized clinical trial. J Int Soc Sports Nutr. 2018;15:18. PubMed PMID: 29713249.

50. Hemmati Maslakpak M, Razmara S, Niazkhani Z. Effects of face-to-face and telephone-based familyoriented education on self-care behavior and patient outcomes in type 2 diabetes: a randomized controlled trial. J Diabetes Res. 2017;2017:8404328. PubMed PMID: 29359166.

51. Shakil-Ur-Rehman S, Karimi H, Gillani SA, Amjad I, Ahmad S, Yaseen A. Response to a supervised structured aerobic exercise training program in patients with type 2 diabetes mellitus-does gender make a difference? A randomized controlled clinical trial. J Natl Med Assoc. 2018;110(5):431-9. PubMed PMID: 30129517.

52. Balducci S, Zanuso S, Cardelli P, et al. Changes in physical fitness predict improvements in modifiable cardiovascular risk factors independently of body weight loss in subjects with type 2 diabetes participating in the Italian Diabetes and Exercise Study (IDES). Diabetes Care. 2012;35(6):1347-54.

53. Castaneda C, Layne JE, Munoz-Orians L, et al. A randomized controlled trial of resistance exercise training to improve glycemic control in older adults with type 2 diabetes. Diabetes Care. 2002;25(12): 2335-41.

54. Wycherley TP, Clifton PM, Noakes M, Brinkworth GD. Weight loss on a structured hypocaloric diet with or without exercise improves emotional distress and quality of life in overweight and obese patients with type 2 diabetes. J Diabetes Investig. 2014;5(1):94-8.

55. Francois ME, Pistawka KJ, Halperin FA, Little JP. Cardiovascular benefits of combined interval training and post-exercise nutrition in type 2 diabetes. J Diabetes Complications. 2018;32(2): 226-33. PubMed PMID: 29198993.

56. Zhang L-Y, Liu T, Teng Y-Q, et al. Effect of a 12 -week aerobic exercise training on serum fetuin-A and adipocytokine levels in type 2 diabetes. Exp Clin Endocrinol Diabetes. 2018;126(08):487-92.

57. Cassidy S, Vaidya V, Houghton D, et al. Unsupervised high-intensity interval training improves glycaemic control but not cardiovascular autonomic function in type 2 diabetes patients: a randomised controlled trial. Diab Vasc Dis Res. 2019;16(1):69-76.

58. Savikj M, Gabriel BM, Alm PS, et al. Afternoon exercise is more efficacious than morning exercise at improving blood glucose levels in individuals with type 2 diabetes: a randomised crossover trial. Diabetologia. 2019;62(2):233-7. PubMed PMID: 30426166.

59. Hangping Z, Xiaona Q, Qi Z, et al. The impact on glycemic control through progressive resistance training with bioDensity(TM) in Chinese elderly patients with type 2 diabetes: The PReTTy2 (Progressive Resistance Training in Type 2 Diabetes) trial. Diabetes Res Clin Pract. 2019;150:64-71. PubMed PMID: 30779971.

60. Hemmati Maslakpak M, Razmara S, Niazkhani Z. Effects of face-to-face and telephone-based familyoriented education on self-care behavior and patient outcomes in type 2 diabetes: a randomized controlled trial. J Diabetes Res. 2017:8404328. 